
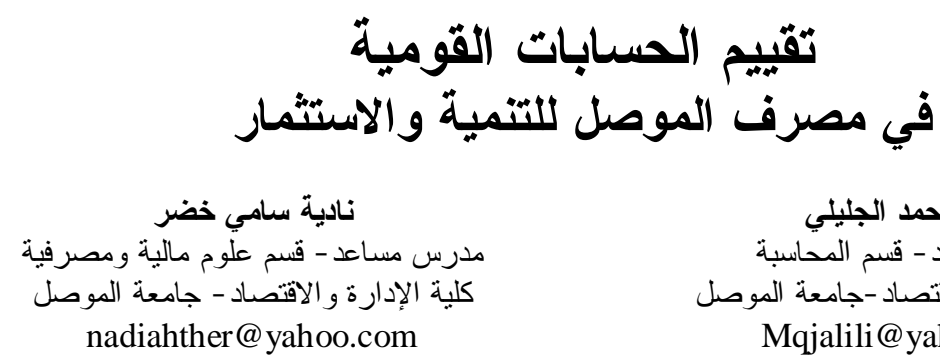
مقداد احمد الجليلي
أستاذ مساعد - قسم المحاسبة الإلمية
كلية الإدارة و الاقتصاد -جامعة الموصل
Mqjalili@yahoo.com

\title{
The Evaluation Of The National Accountling System In Mosul Bank Fof Development And Investment
}

\author{
Mokdad A. Al Jalili \\ Assistant Professor \\ University of Mosul
}

\author{
Nadia S. Khudir \\ Assistant Lecturer \\ University of Mosul
}

\begin{abstract}
The united accounting system issued by the Revolution Leadership Council No. 380 in $5 / 4 / 1979$ is initiated to produce the required data to serve accounts on the national level and an attempt to connect accounts of economic unit with the national accounts. In the beginning of the system application, the banking sector is excepted despite its importance. So, the researchers' efforts have not been wasted, where the application of accounting system in banking sector has been proposed. As a result, the accounting system was issued and applied in banks in 1988. The aim of this sort of application was to connect the banking
\end{abstract}

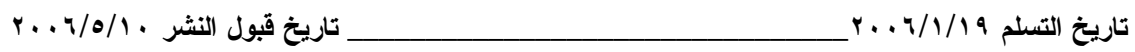


accounts with the national accounts in order to provide the appropriate data for the comprehensive economic planning.

As for Mosul Bank for Development and Investment may apply the unified accounting system and the absence of resources which connect the bank accounts with the national accounts, the researcher presented a field study in Mosul Bank and demonstrated the bills of the national accounts and connected the bank accounts with the national accounts.

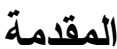

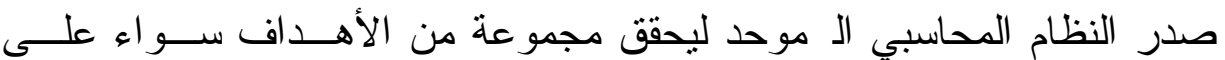

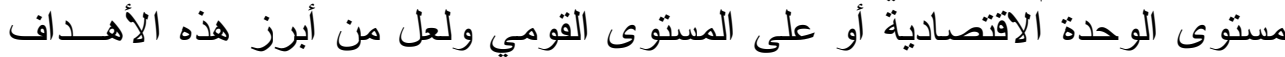

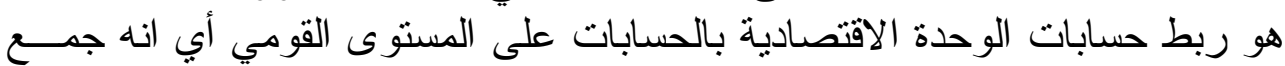

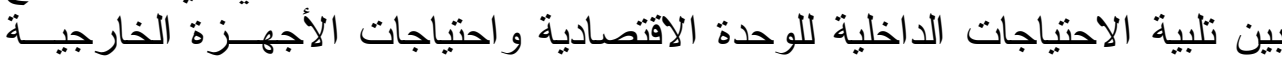

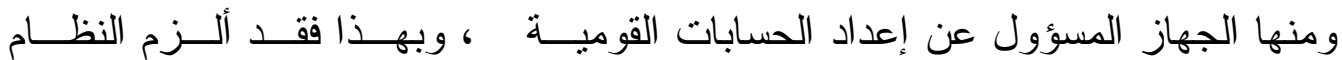

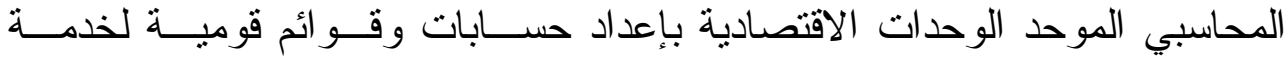

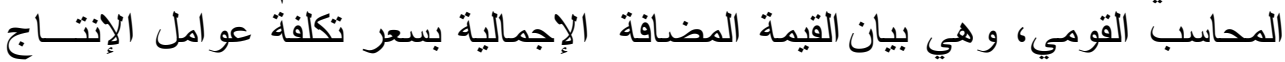

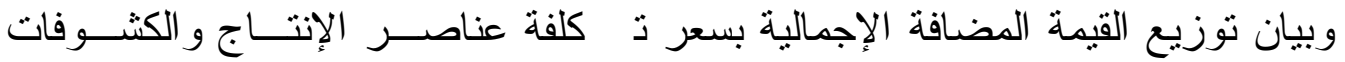

\section{مشكلة البحث}

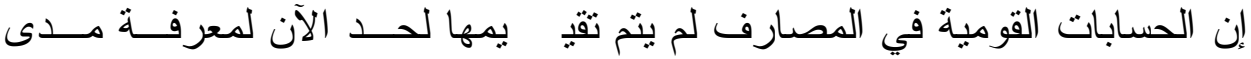

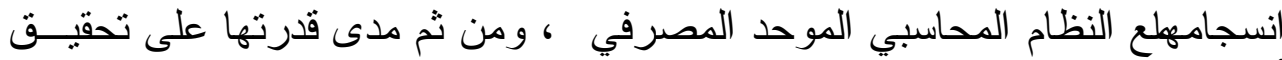

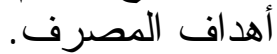

$$
\text { فرضية البحث البحث إلى الفرضية الآتية: }
$$

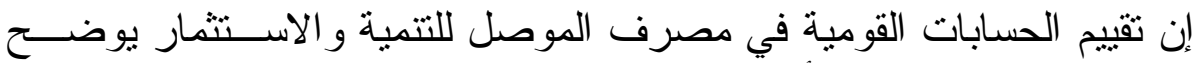

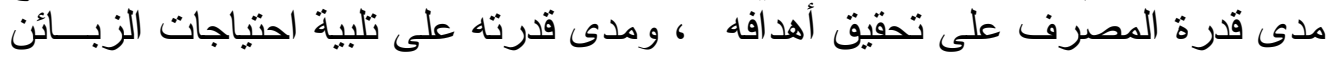

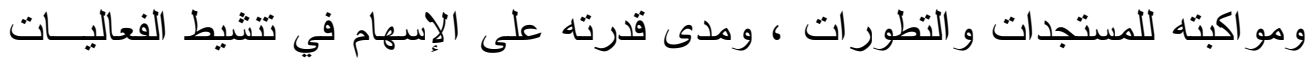

الاقتصادية و المالية.

أهمية البحث أهمية البحث في التعرف على الحسابات القومية في مصرف الموصل

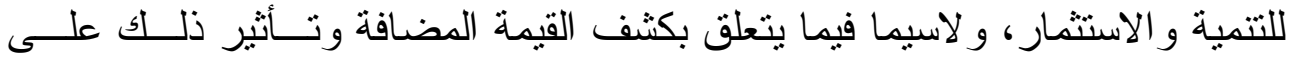

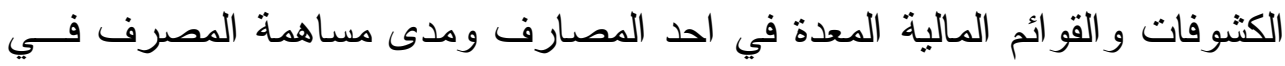

$$
\text { هدف البحث الناتج المحلي الإجمالي. }
$$


ا. ـ التعرف على تركيبة الحســابات القوميــة فــي مصــرف الموصــل للتنميـــة

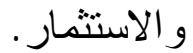

r. تقييم الحسابات القومية في مصرف الموصل للتنمية و الاستثمار . منهج البحث

اعتمد البحث على المنهج الوصفي في معالجة الجانب النظري للبحث مستعيناً

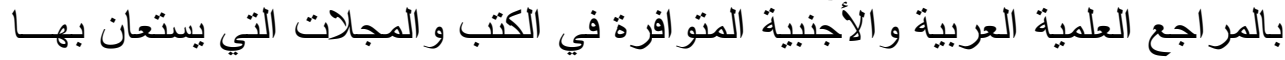

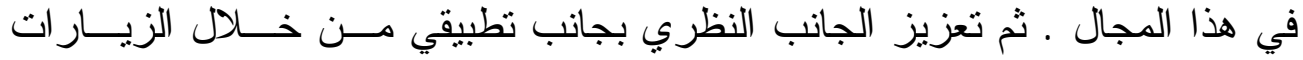

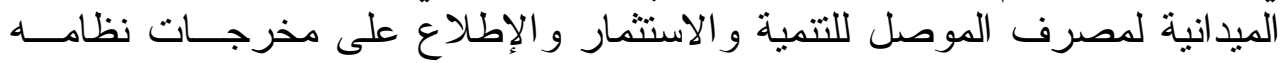

ووصو لا إلى أهداف البحث فقد تم تقسيمه إلى مبحثين وهما: المحاسبي.

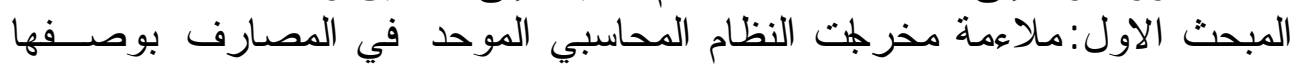
مدخلات لنظام المحاسبة القومية.

المبحث الثاني: إعداد الحسابات القومية في مصرف المحية لقودل للتنمية و الاستثمار .

\section{ملاءمة مخرجات النظام المحاسبي الموحد في المصارف بوصفها

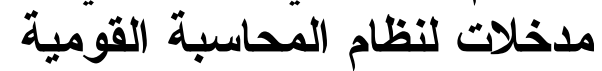

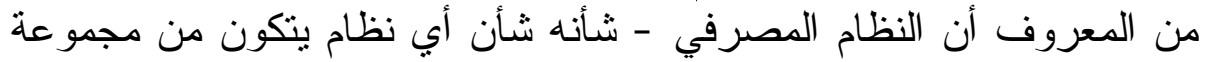

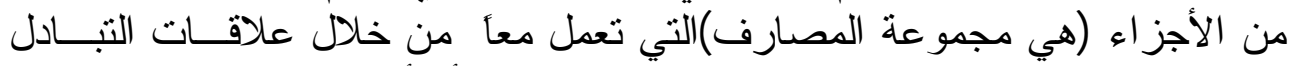
و التز ابط حسب قُ اعد و إجر اءات محددة لتحقيق هدف أو أهد أهداف معينة .

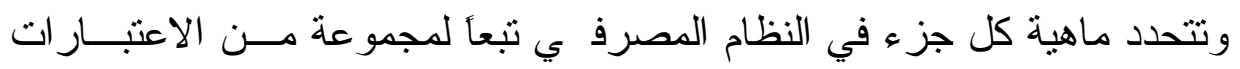

$$
\text { • • طبيعة النشاط الذي يز اوله الجزءء. }
$$

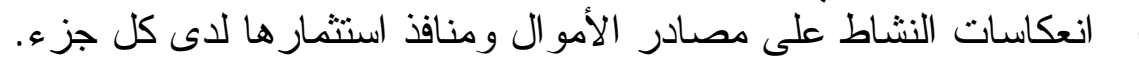

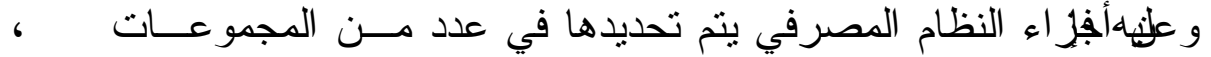

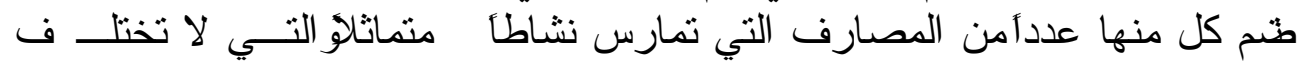
مو اردها المالية و أوجه استثمار ها.

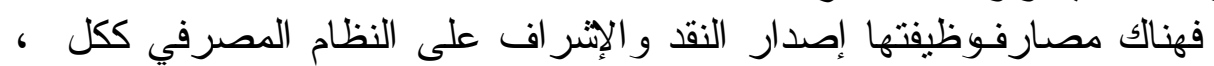

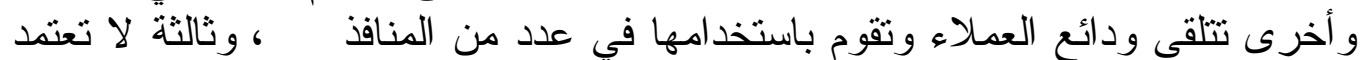

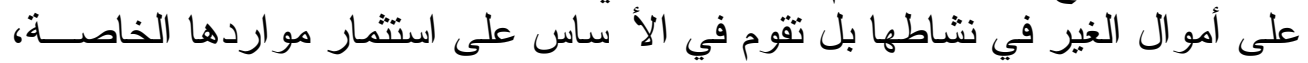

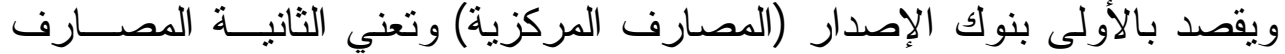

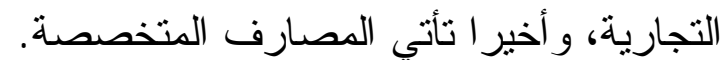

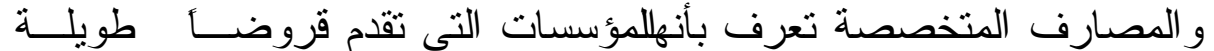

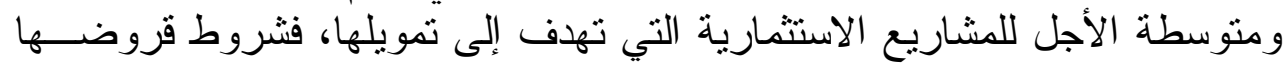

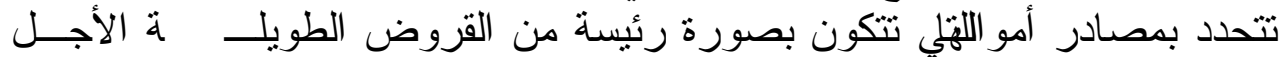


وبشروط ميسرة من الحكومة و المؤسسات المحلية و الدوليــة (لحــور اني،9 و من هنا تختلف المصارف المتخصصة Specialized Banks عن المصــارف

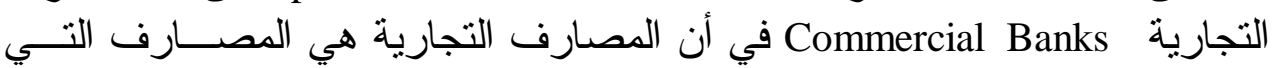

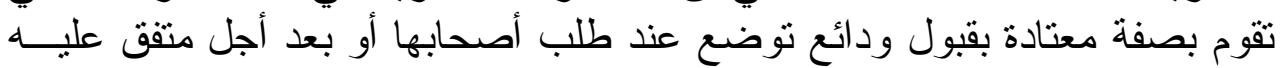

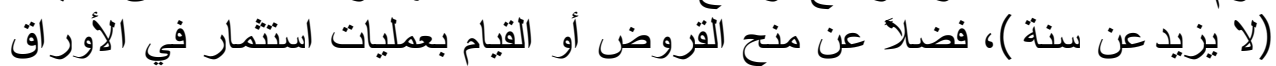

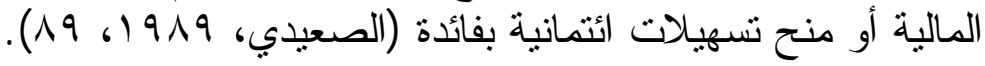

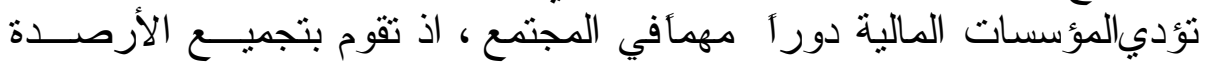

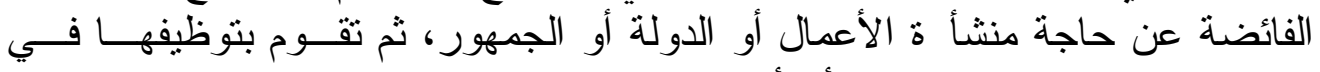

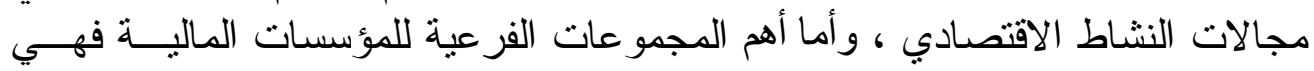

:(Fredc,1989, 5)

$$
\begin{aligned}
& \text { ا ـ المصارف التجارية. } \\
& \text { r. المصارف المتخصارف التحارية. }
\end{aligned}
$$

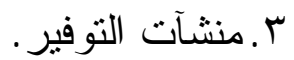

$$
\begin{aligned}
& \text { ع ـ منشآت الاستثمار . }
\end{aligned}
$$

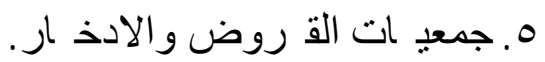

$$
\begin{aligned}
& \text { 7. ثـ ركات الت امين. }
\end{aligned}
$$

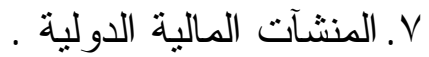

$$
\begin{aligned}
& \text { ^. منشآت الوساطة المالية. }
\end{aligned}
$$

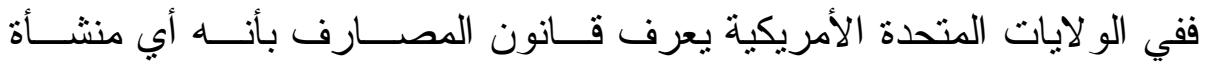

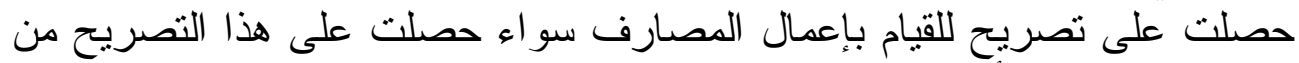

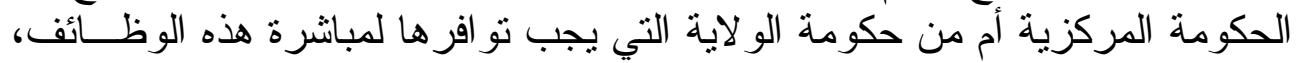

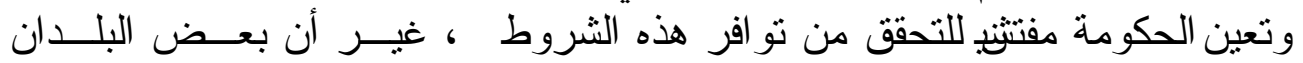

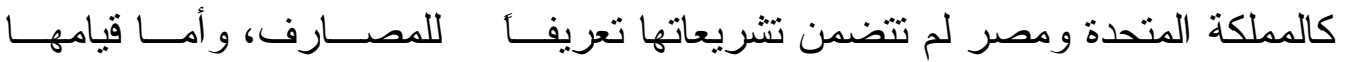

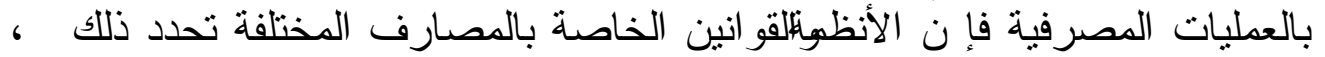

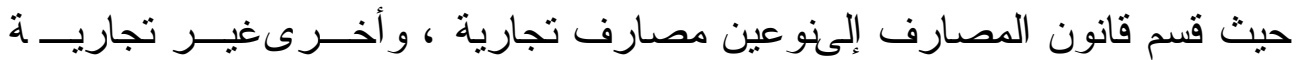

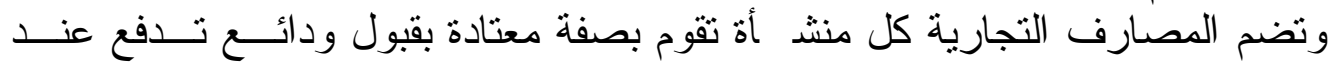

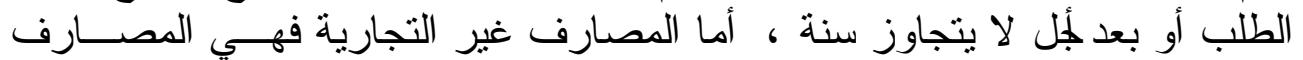

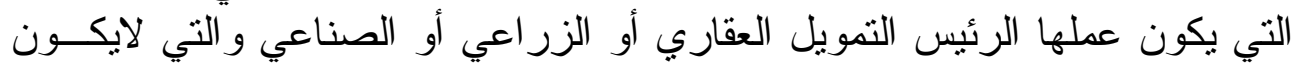

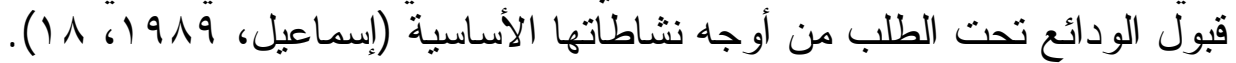

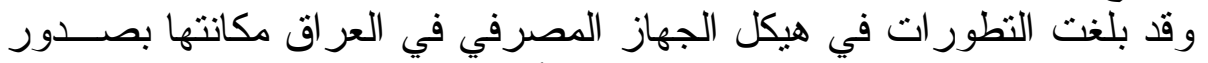

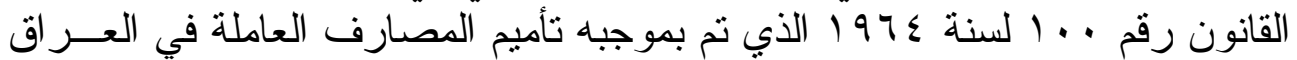

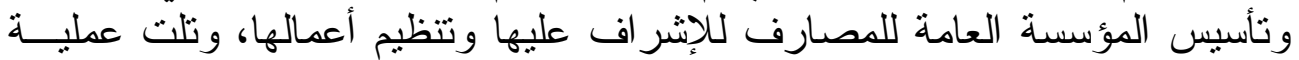

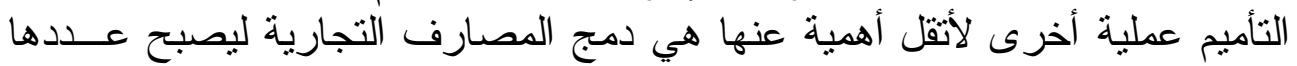

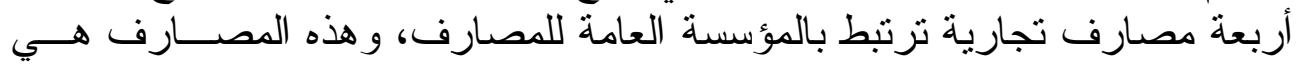


مصرف الر افدين،البنك التجاري العر اقي بنك الاعتماد العر اقي وبنك بغداد ، وفئي

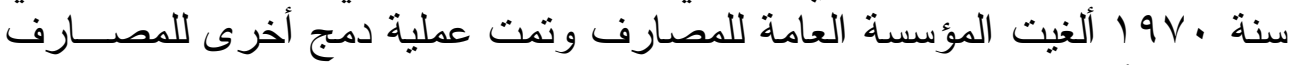

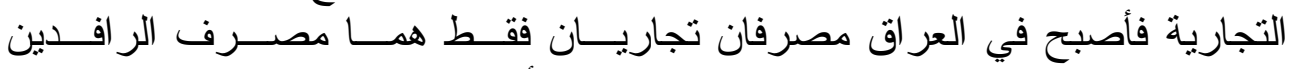

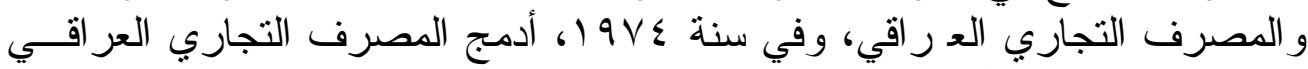

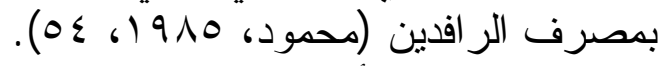

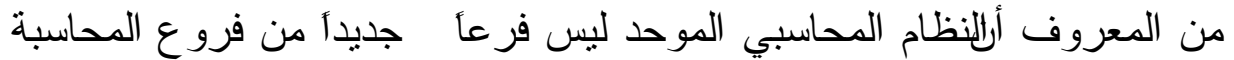

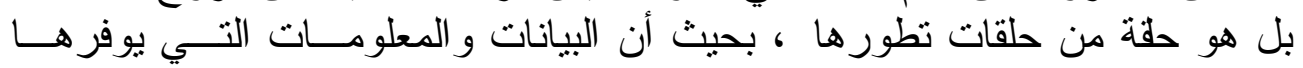

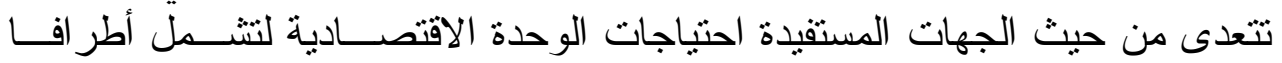

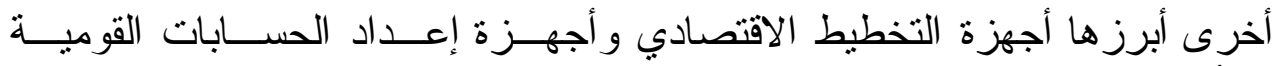

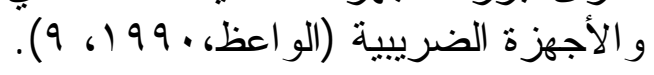

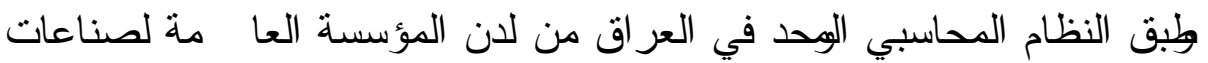

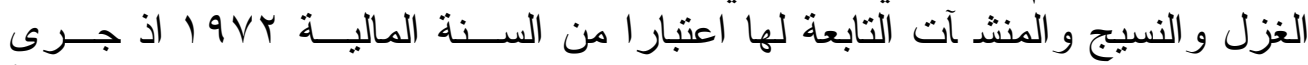

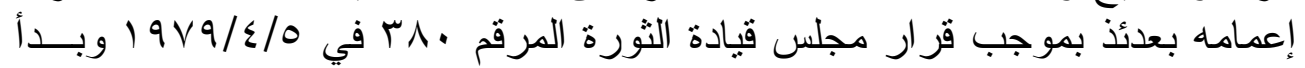

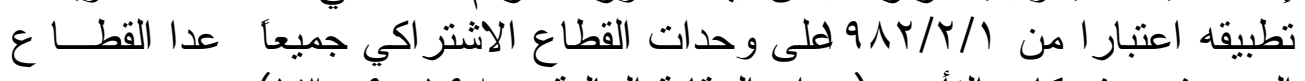

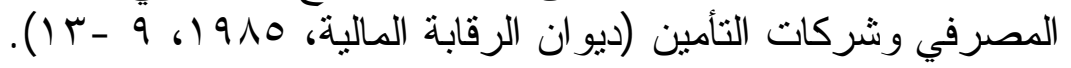

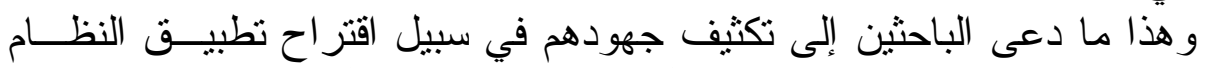
المحاسبي الموحد في القطاع المصرفئ المى نكي (محمود،

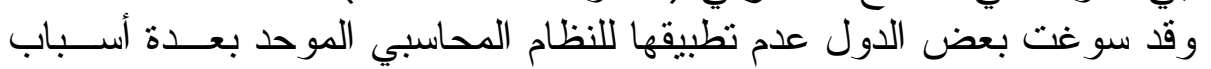

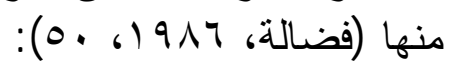

أولاً - اختلاف طبيعة النشاط في وحدات المصارف الف عن طبيعة النشاط في الوحدات

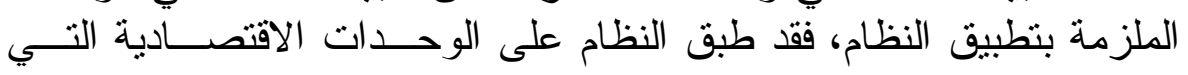

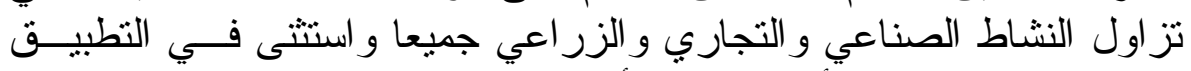

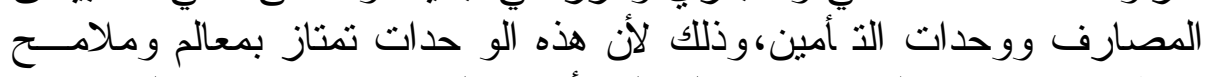

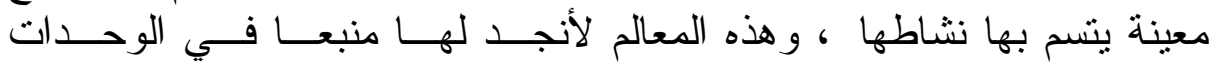

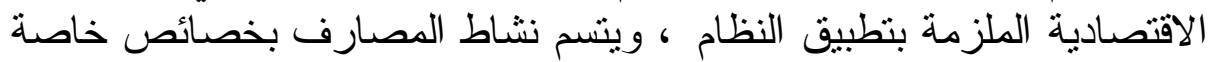

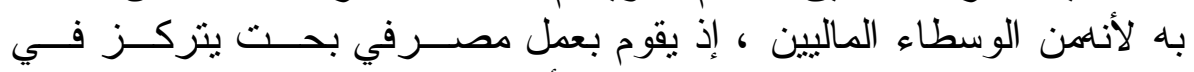

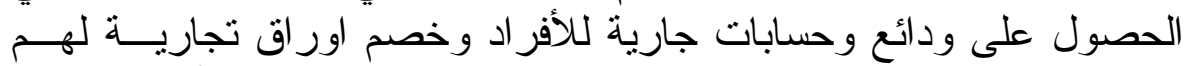

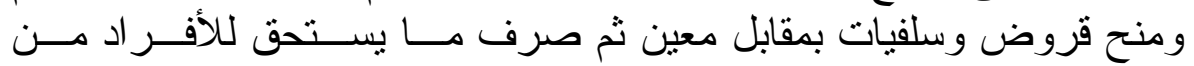

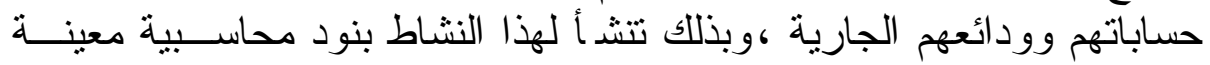

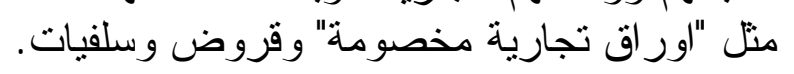

ثانيلَتنلاف مسميات البنود المحاسبية الواردة في الدليل المحاسبي بال نظام عـن

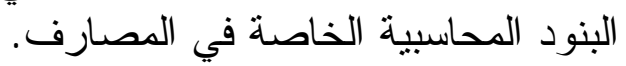

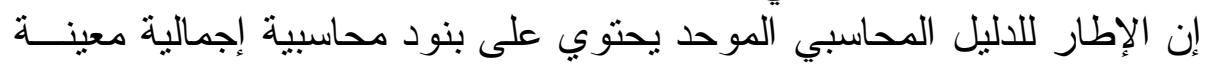

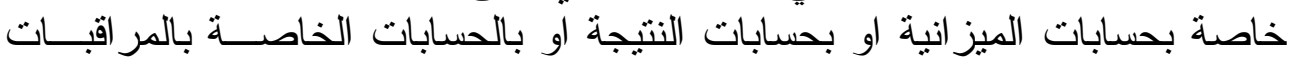

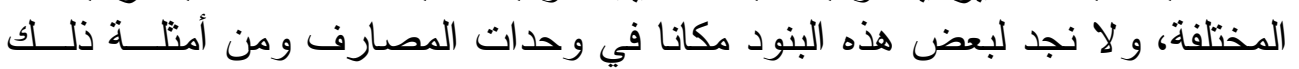


البنود الاتية:المشروعات تحت التفيذ ، المخزون،مشنريات بغرض البيع .......الخ

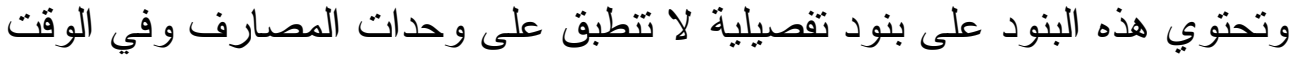

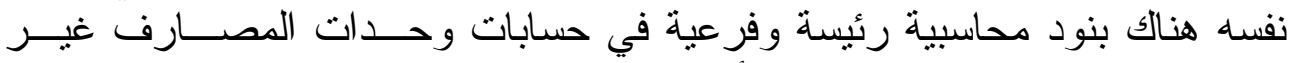

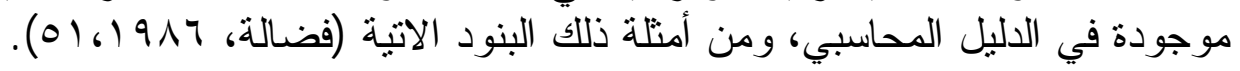
الموجودات

$$
\text { r. أ. ذهب اق تجارية مخصومة }
$$

r. صكوك وحو الات مالية و عملات أجنبية تحت التحصيل

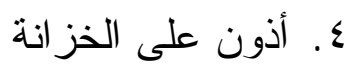

المطلوبات

ا . صكوك وحو الات وخطابات اعتماد دورية مستحقة الدفع. r. ب مبالغ مقترضة من البنك المركزي r. التز امات تجاه العملاء نظير اعتمادات مفتوحة بالعملات العزي الأجنبية ع. التز امات عرضية

ثالثاً - اختلاف الأسس و القو اعد المحاسبية الخاصة بتقيــيم الأصـــول و الالنز امــات

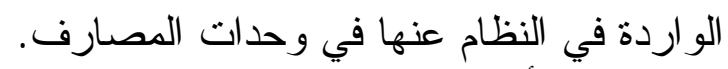

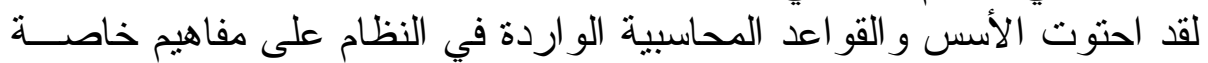

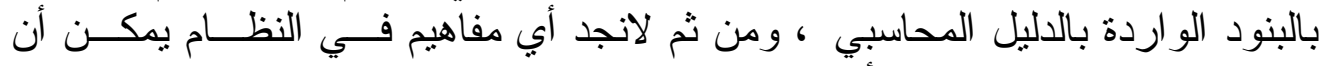

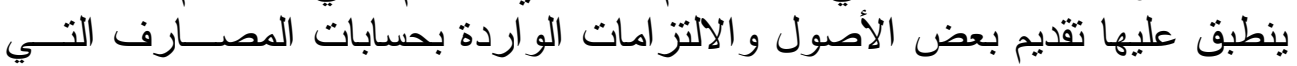

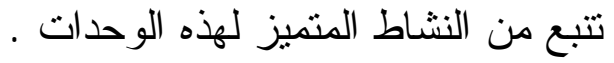

رابعاً - اختلاف عرض القو ائم و الحسابات الختامية ومحتوياتها الواردة فــي النظــام

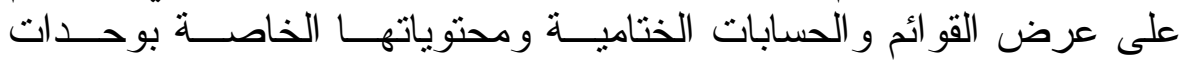
المصارف.

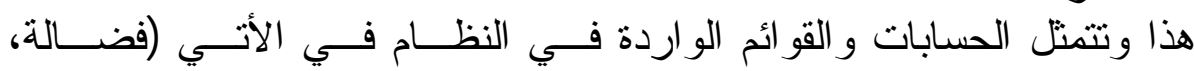
:(Or6) 917

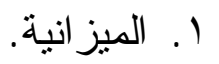

r. بائمة الاستخدامات و المو ارد د. r. عساب العمليات الجارية. ع. عساب الإنتاج و المتاجرة.

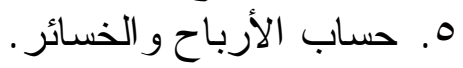

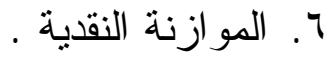

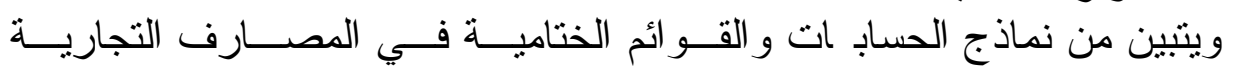
و المصارف العقارية و المصرف الصناعي مدى اختلاف المسميات الموجــودة فـــي 
هذه النماذج عن المسميات المحاسبية في الحسابات و القو ائم الختامية في النظام، كما

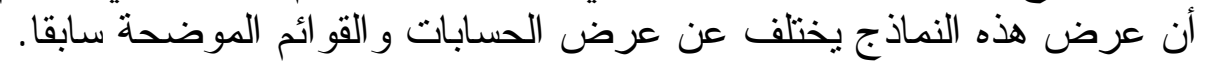

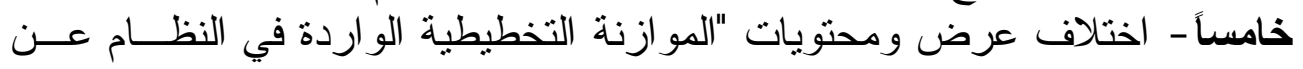

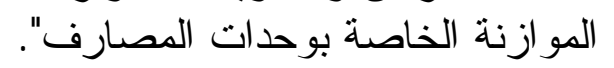

أثنار النظام إلى أن الوحدة الاقتصادية ملزمة بإعداد موازية إزنة تخطيطية تتضمن

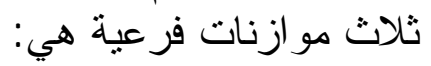
ا ب. الموازنة العينية r. ب. الموازنة المالية

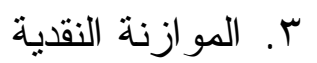

و أورد النظام بـ عض القو اعد الخاصة بإعداد المو ازنات، كما أورد نماذج معينة

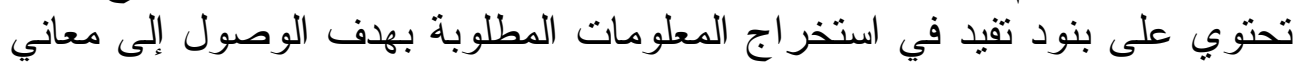

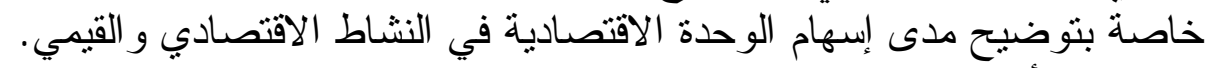

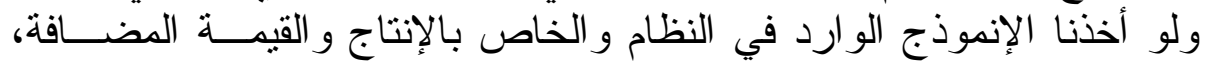

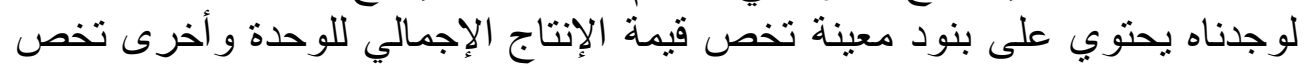

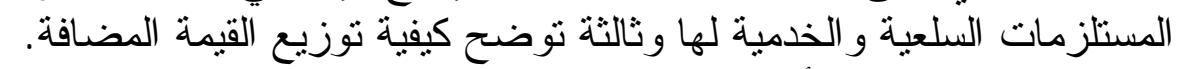

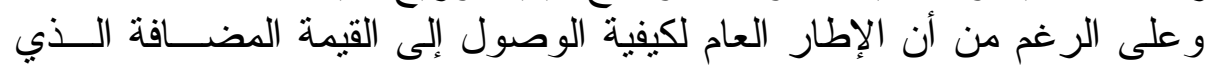

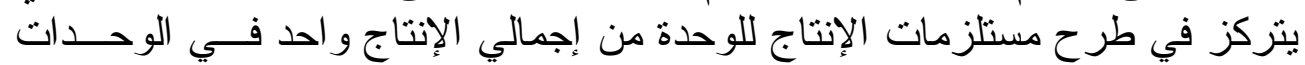

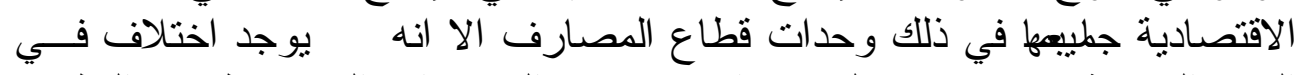

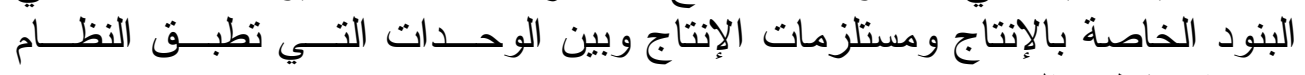

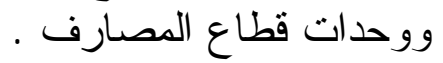

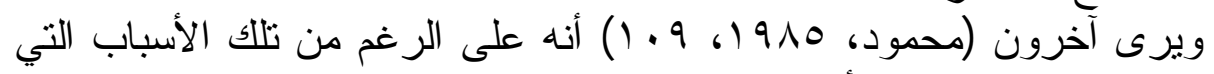

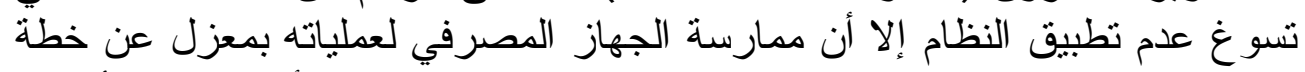

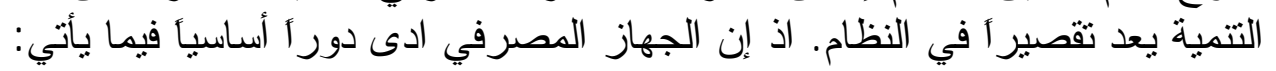

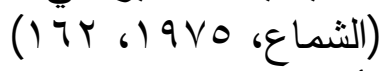

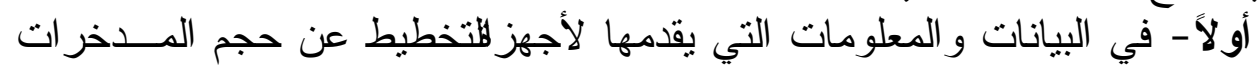

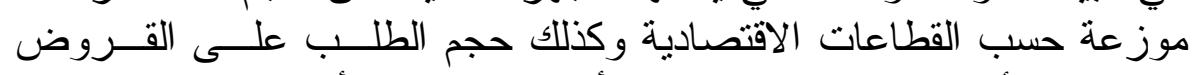

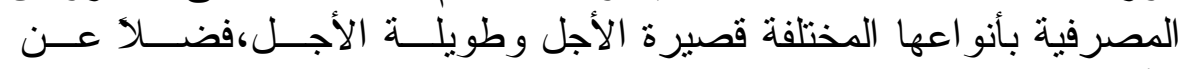

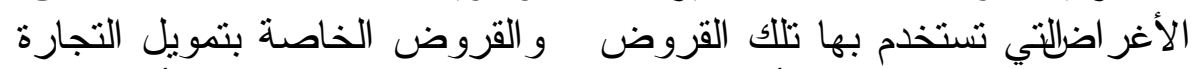

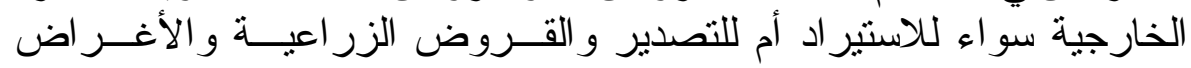

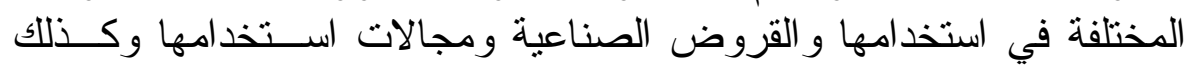
القروض التعقارية.

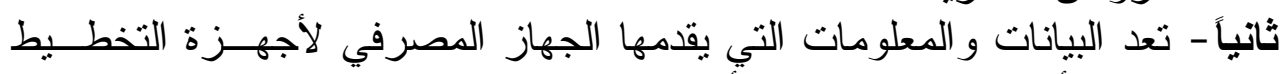

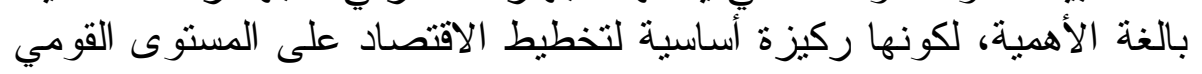

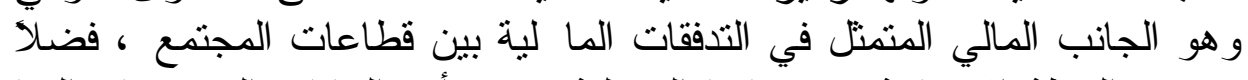

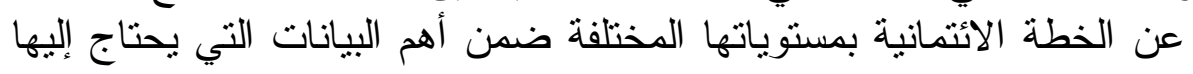




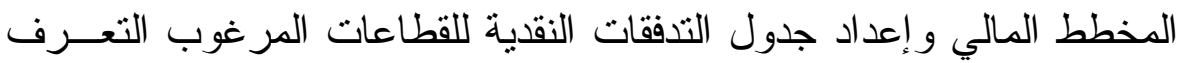
على أوجه نشأطها المالي و على مستوى عال مالى من التفصيل.

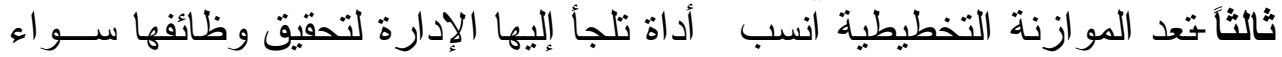

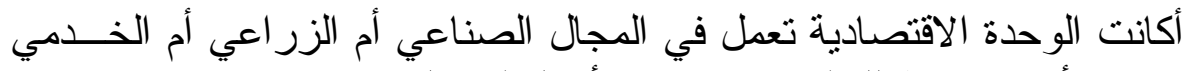

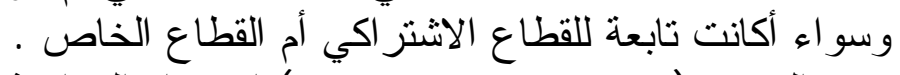

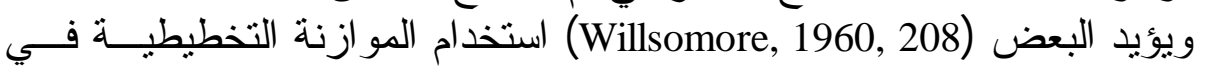

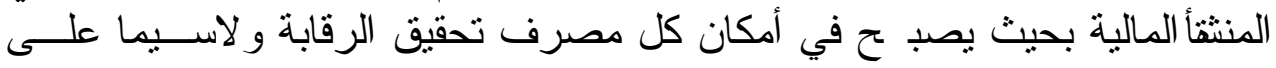
المصروفات الإدارية وذلك باستخدام الموازنات التي تلبي الاحتياجات الانية:

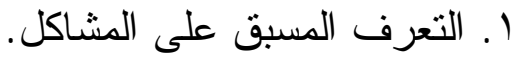
r. تحقيق الرقابة الفعالة.

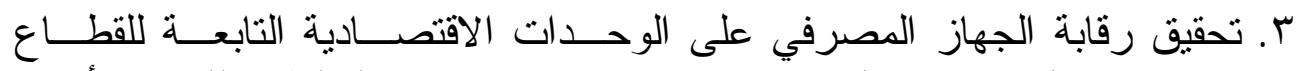

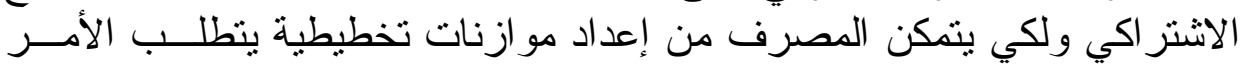

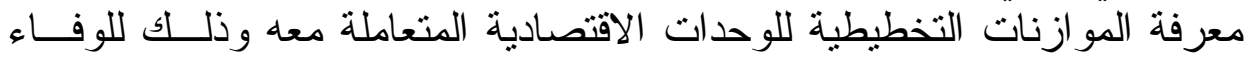
بمتطلبات تتفيذ تلك الخطط.

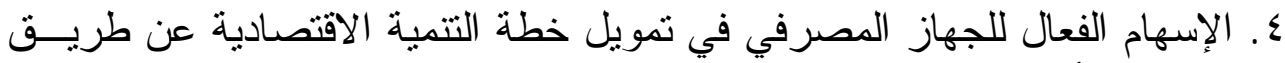

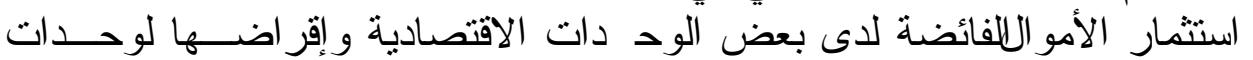
تحتاج لتلك الأمو ال.

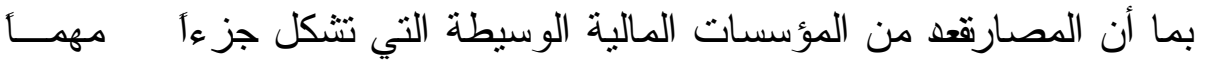

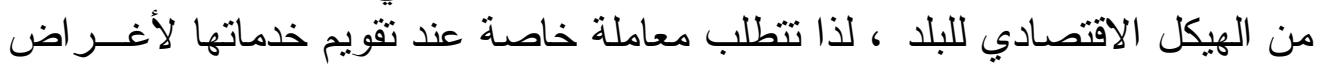

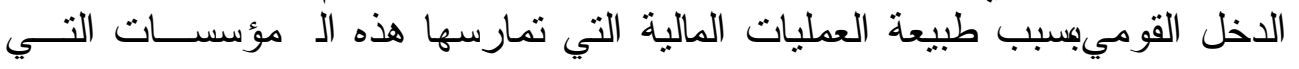

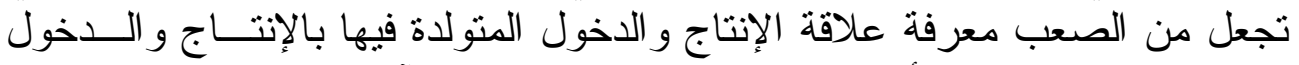

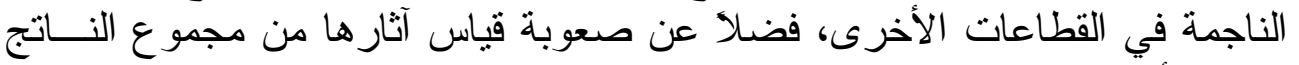

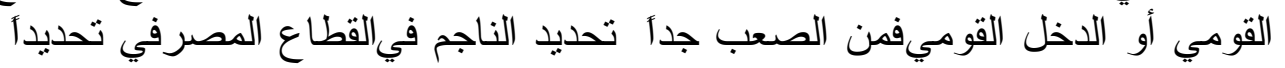

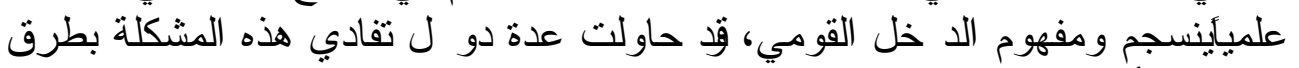

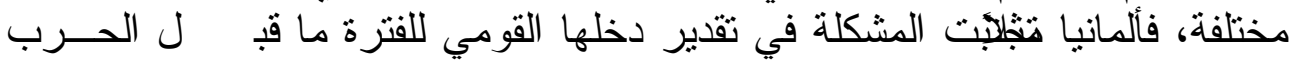

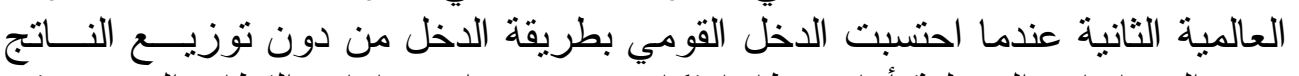

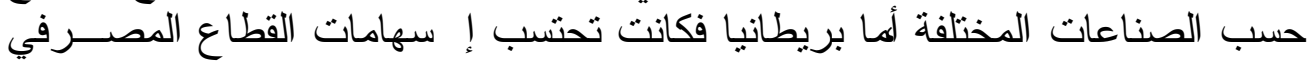

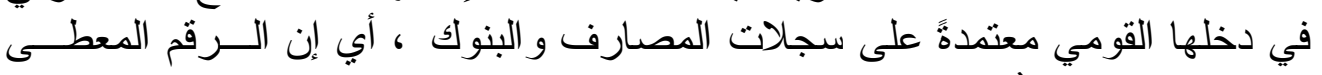

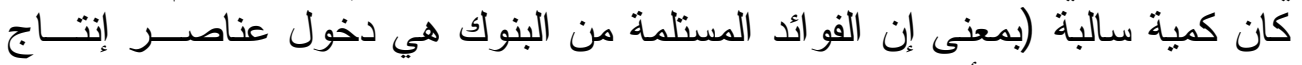

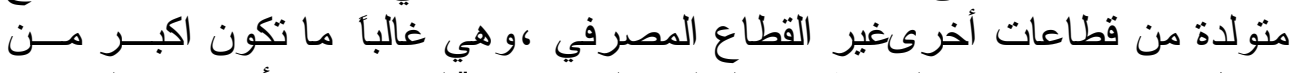

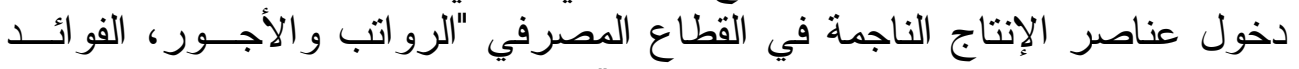

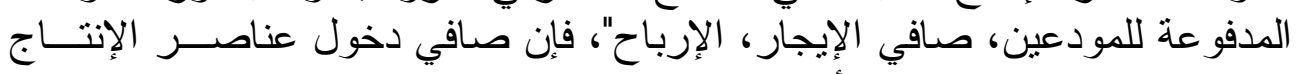

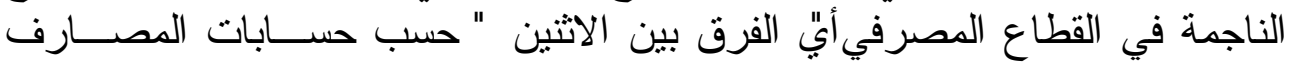

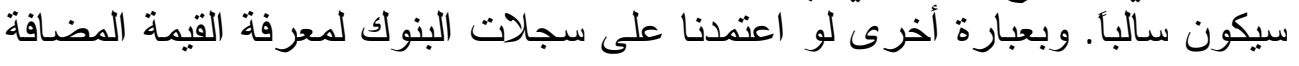

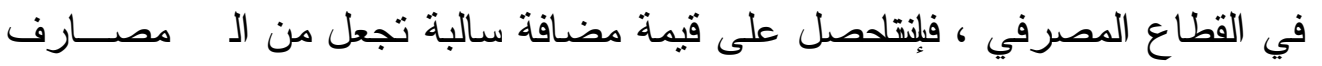




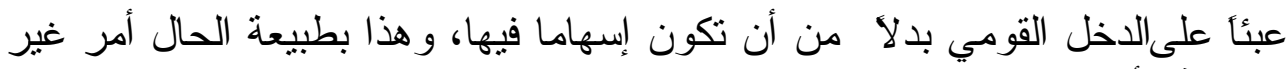
منطقي). أما استر اليا فقد حذفت القطاع المصرفي من دخلها القومي للفترة 19 ـ 19 .1941

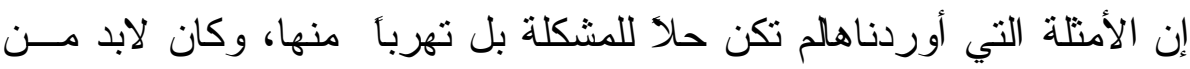

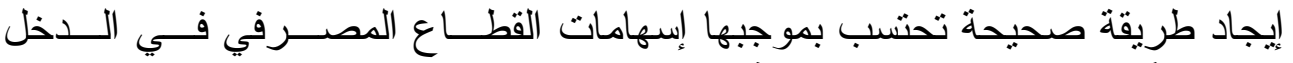

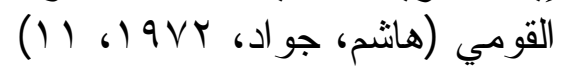

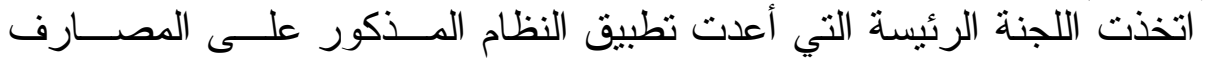

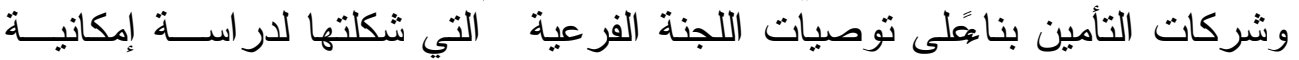

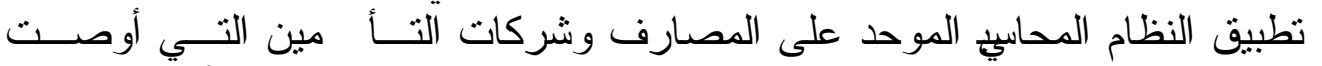

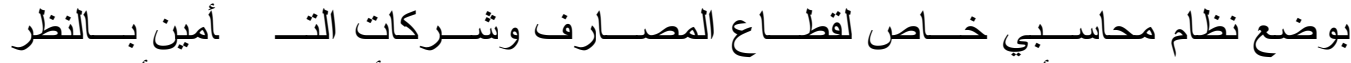

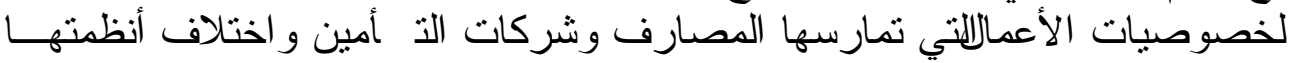

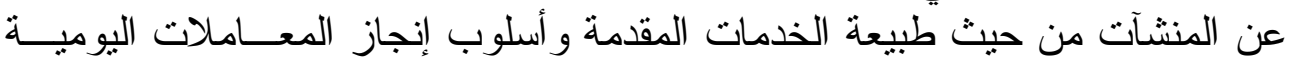

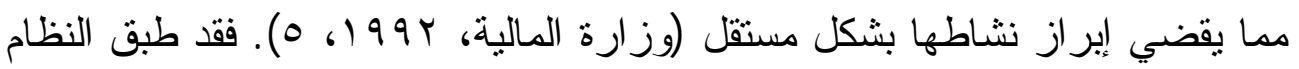

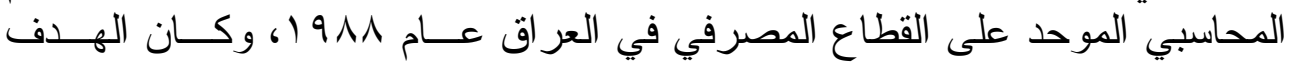

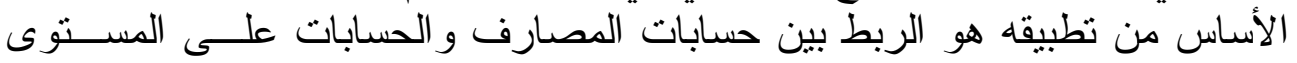
القومي.

\section{إعداد الحسابات القومية في مصرف الموصل للتنمية والاستثمار}

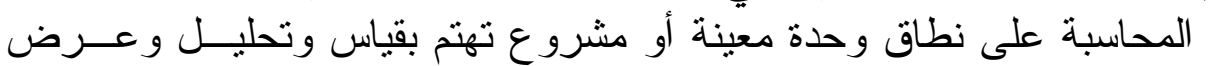

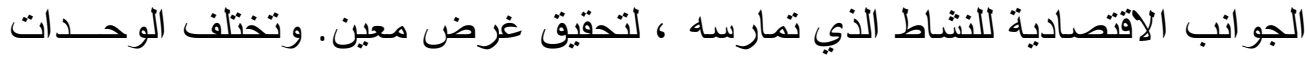

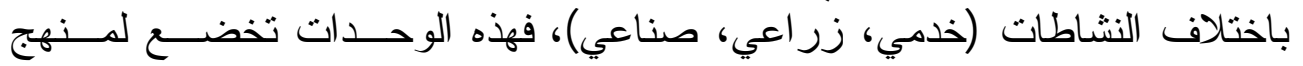

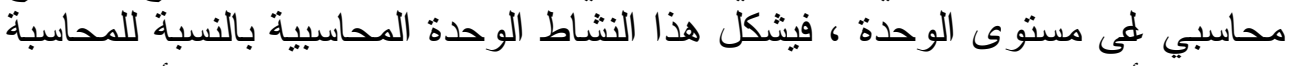

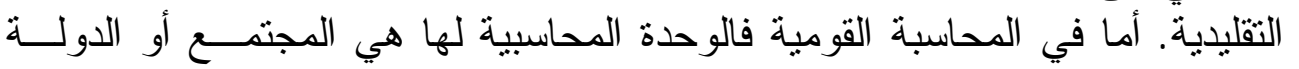

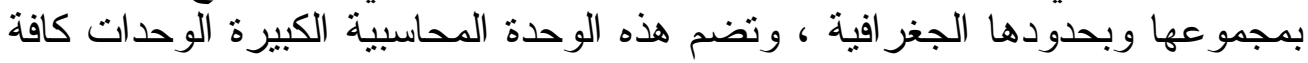

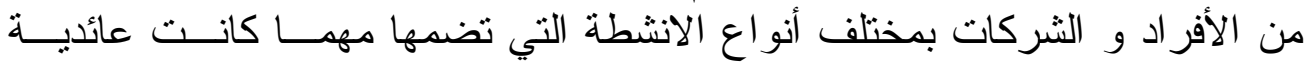

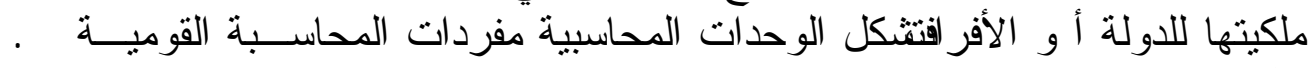

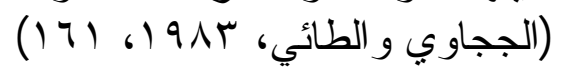

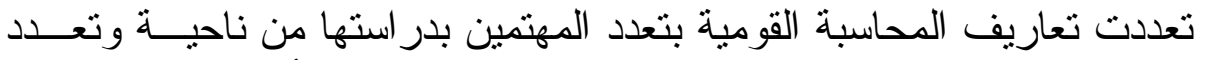

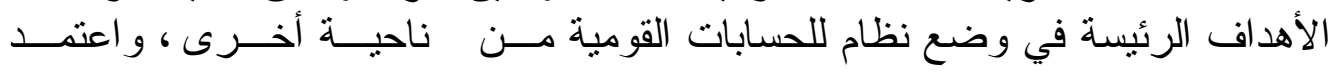

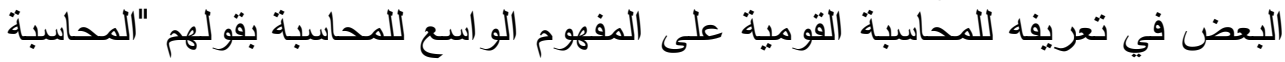

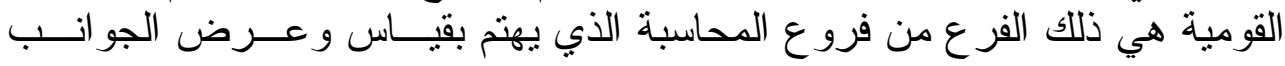

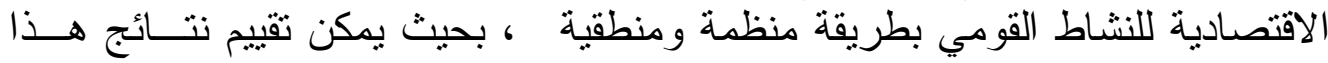

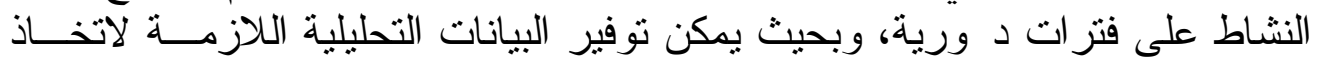
القرار ات وترشيد السياسات القومية ، فهي منهج محاسبي يهدف دات إلى إعطاء مضدون

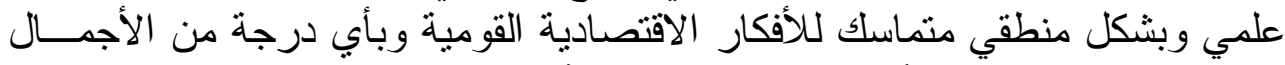

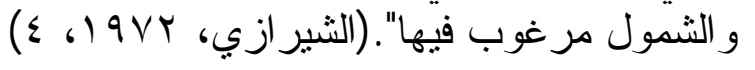


و عرفها آخرون بأنها "العلم الذي يقوم على مجمو عة من المبــادئ و الأسـائ.

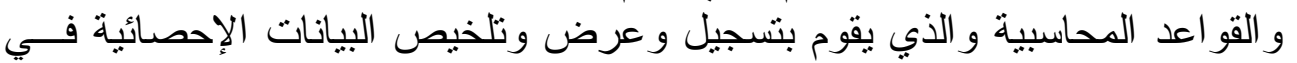

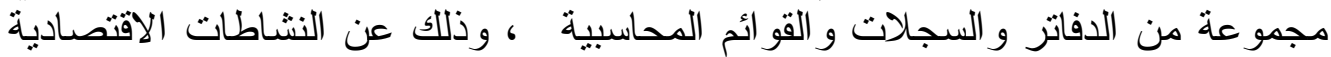

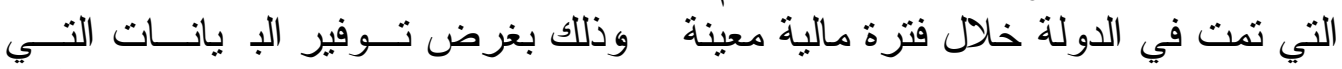

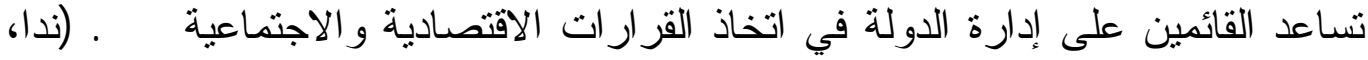

(1) 6 ) 99 .

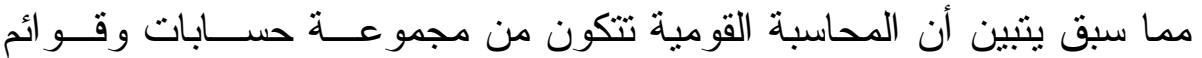

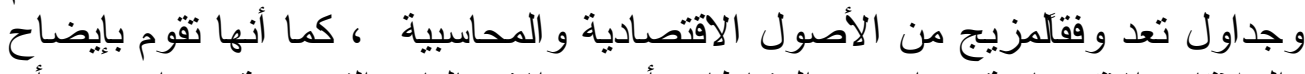

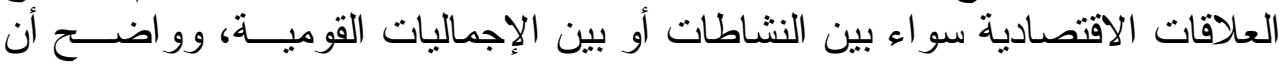
هذين التعريفين لم يتعرضا لنشاط الأئه الوحدة المحاسبية.

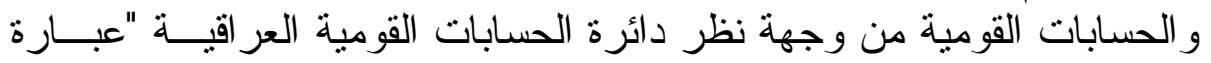
عن عرض وتحليل النشاط الاقتصادي للوحدة الاقتصادية وبيان مدى دمى مساهماتها في

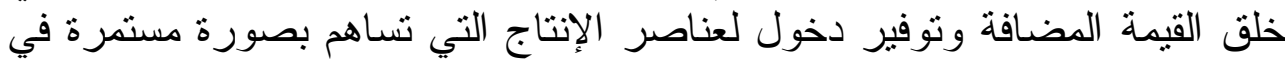

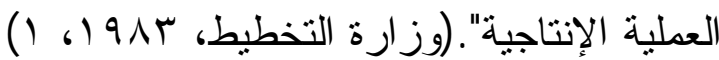

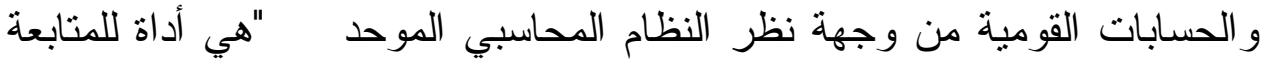

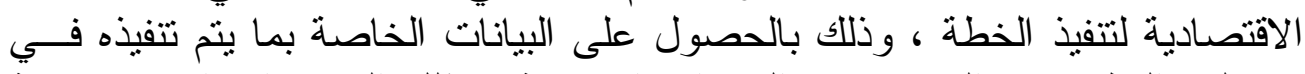

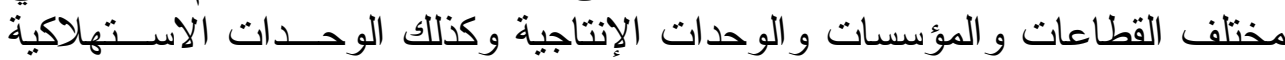

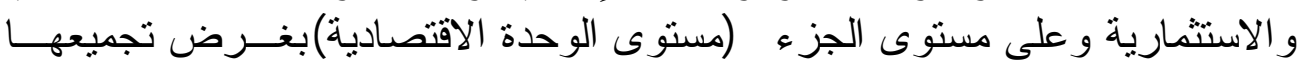

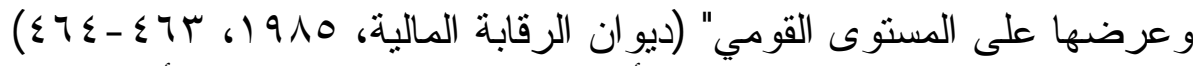

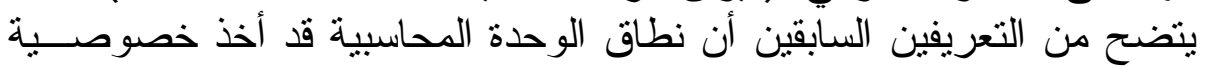

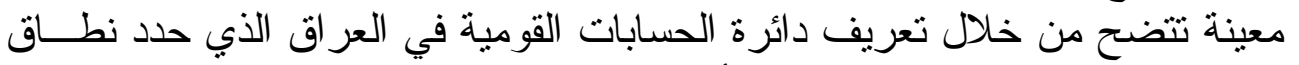

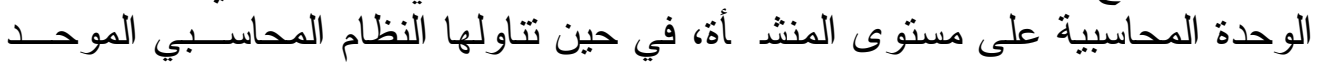

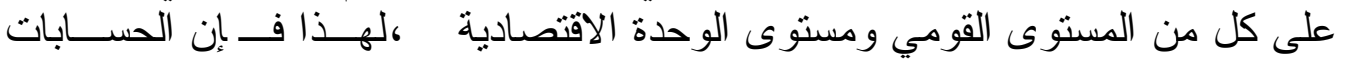

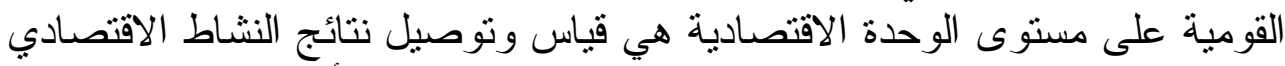

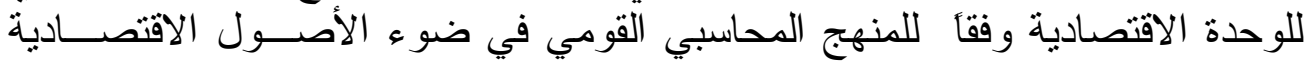

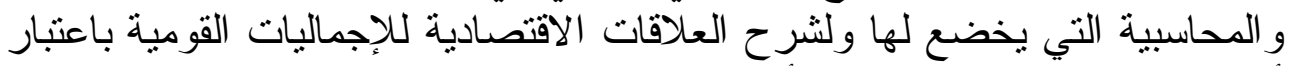

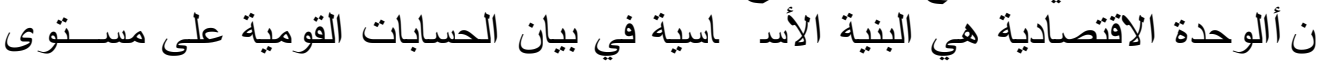

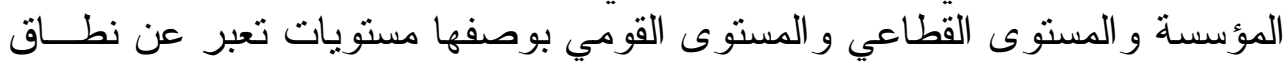

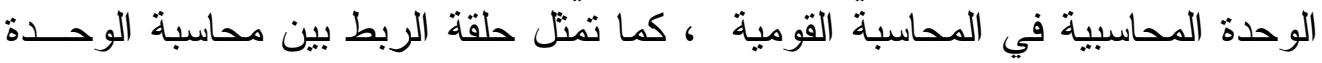

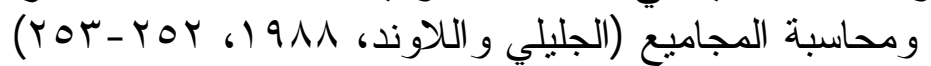

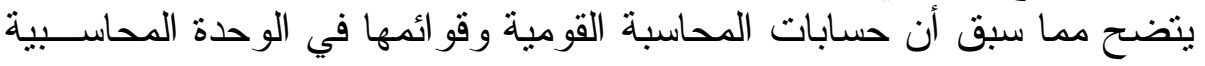

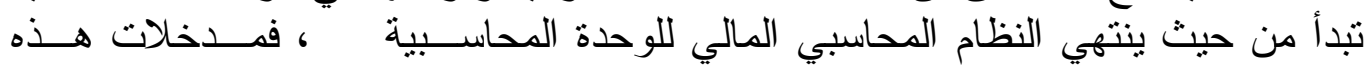

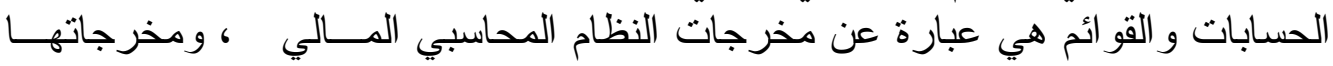

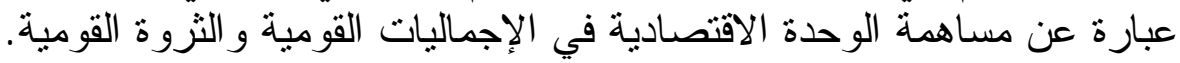

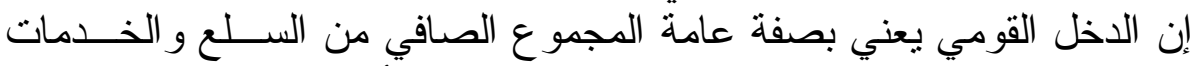

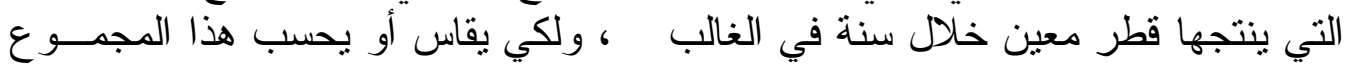




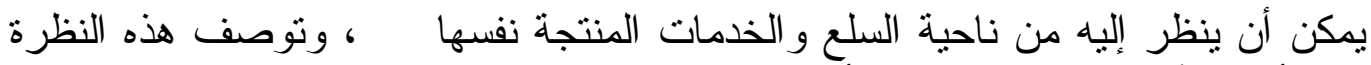

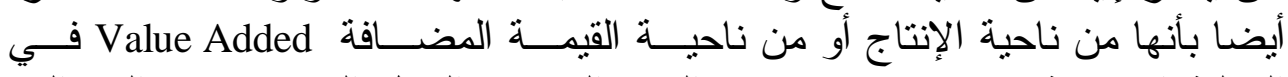

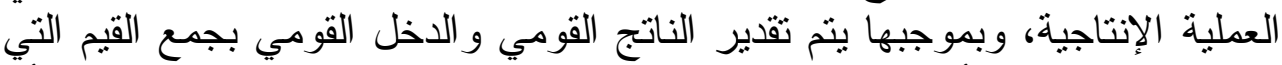

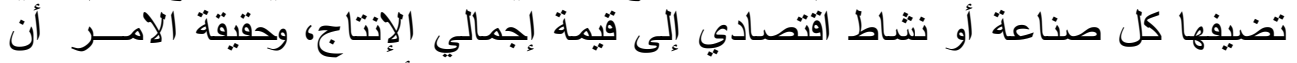

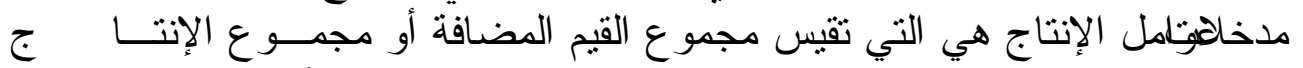

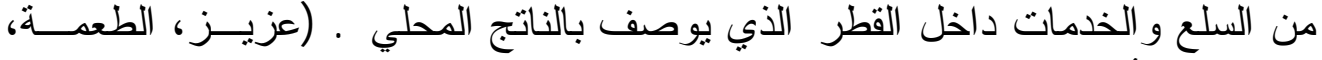
(ON- ro

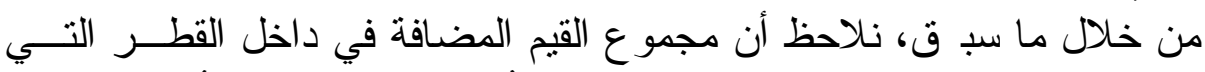

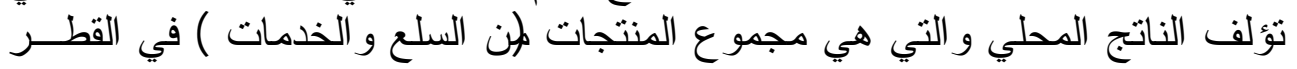

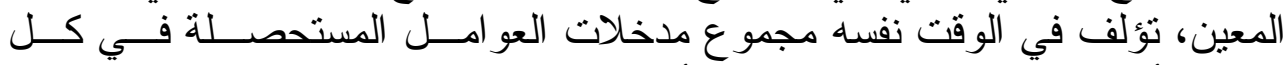

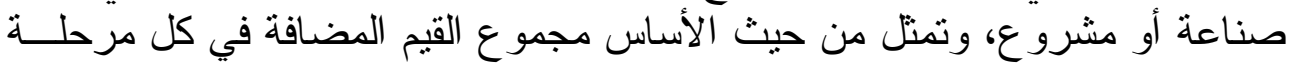
من مر احل الإنتاج.

من هنا فان القيمة المضافة تتألف من الأجور و الرواتب و الإيجــار و الفائــدة

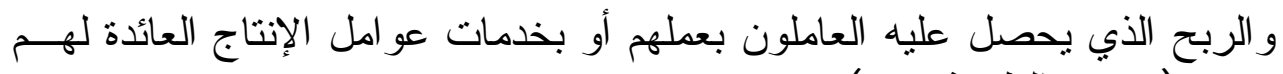

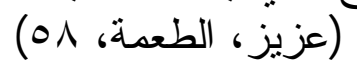
وفيما يأتي الحسابات القومية على مستوى الوحدة الاقتصادية:

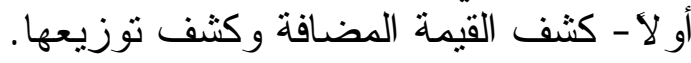
ثانياً - حسابات العمليات الجارية.

أولاً - كشف القيمة المضافة وكشف توزيعها

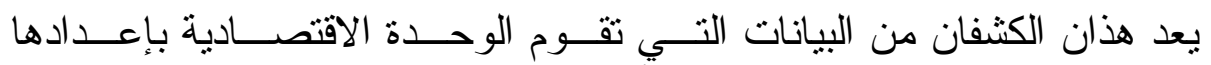

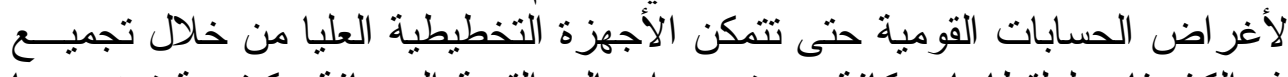

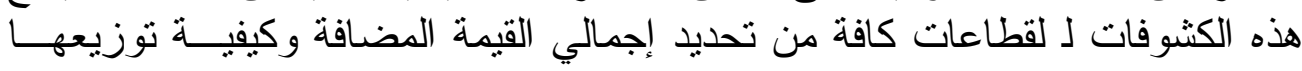

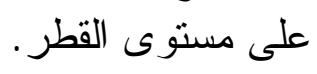

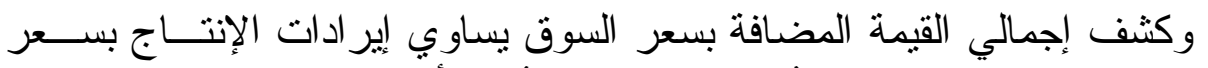

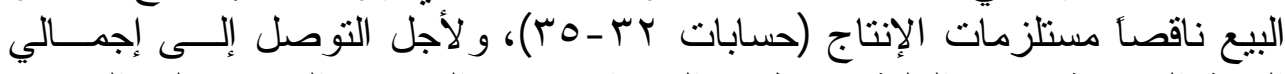

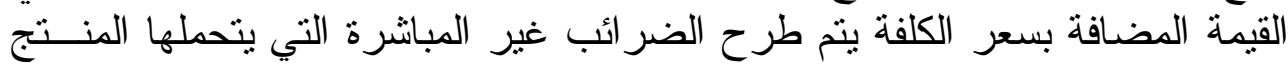

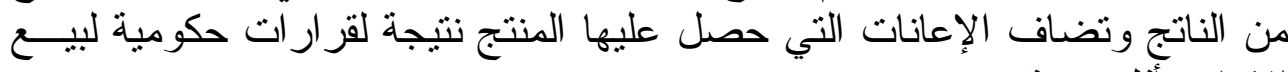
ويرى البعضلن ألقيمة المضافة على على المستوى الـ قومي تعني الناتج المحلــي

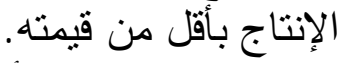
الإجمالي، دن هنا تتوز ع بين الجو الب الب الاتية:

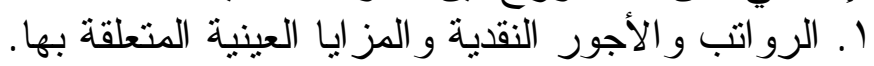

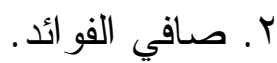

$$
\begin{aligned}
& \text { r. عافي إيجار ات الأر اضي. الذي. } \\
& \text { ع. الاندثار ات. }
\end{aligned}
$$




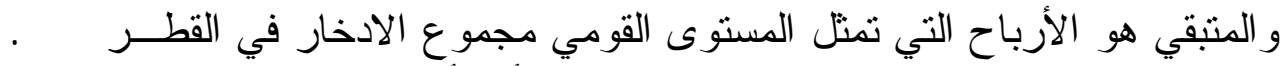

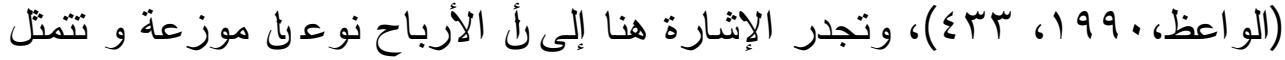

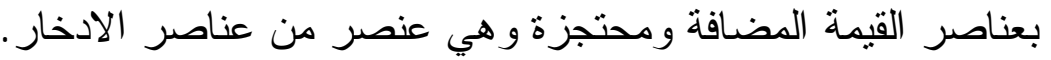

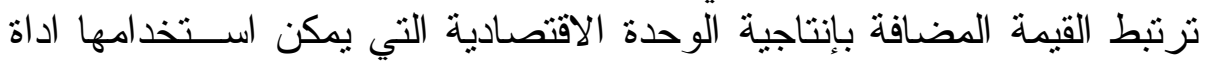

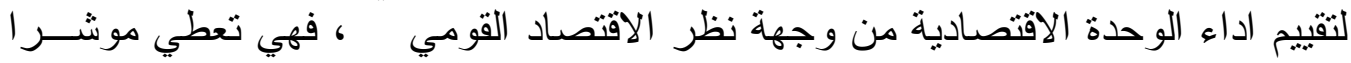

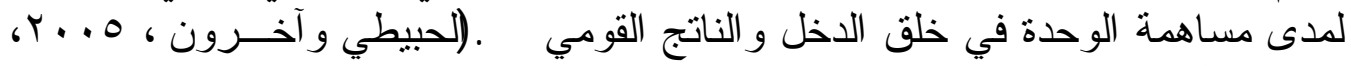

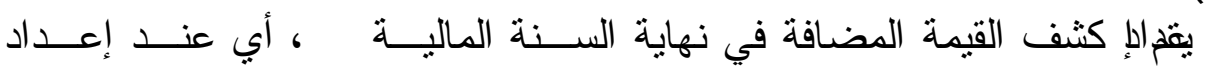

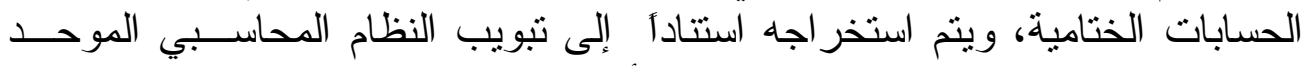

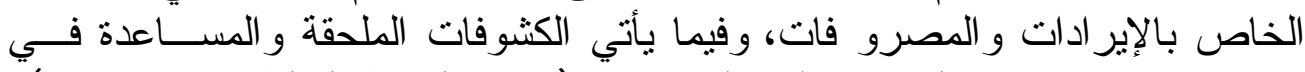

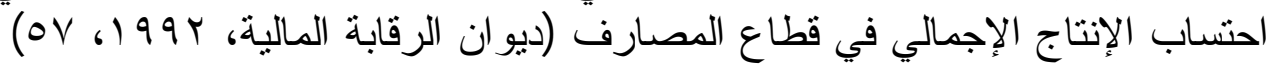

\section{الجدول الاجمالية}

كشف توزيع القيمة المضافة الإجمالية بسعر تكلفة عوامل الإنتاج

\begin{tabular}{|c|c|}
\hline التفاصيل & رقم الدليل \\
\hline 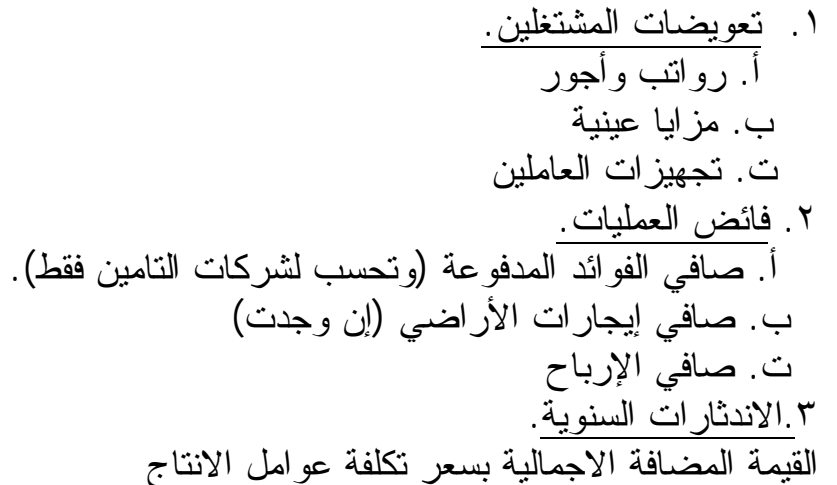 & 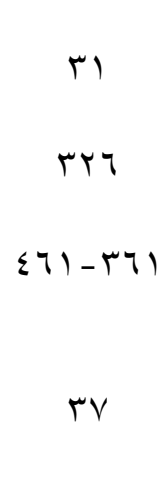 \\
\hline
\end{tabular}




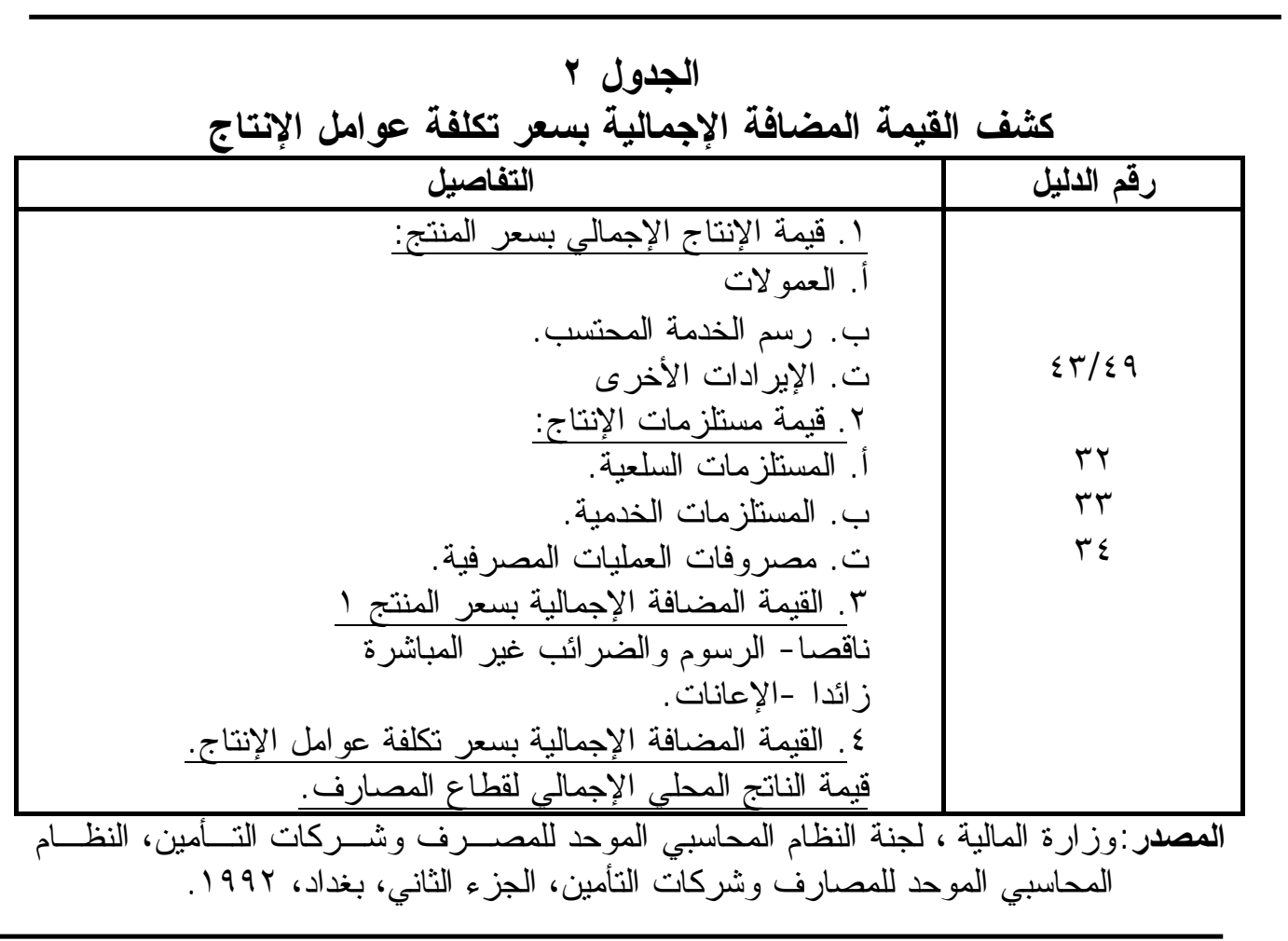

\section{ثانياً - حسابات العمليات الجارية}

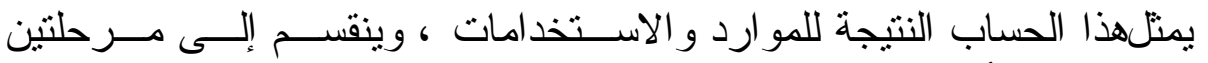

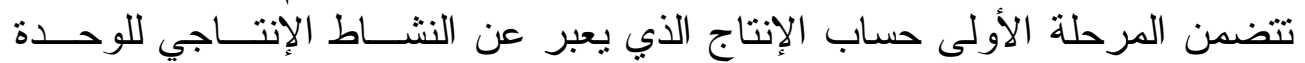

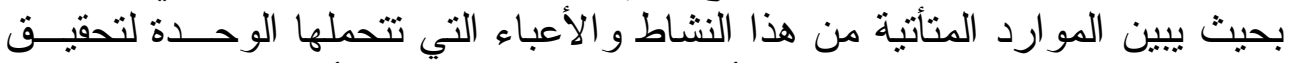

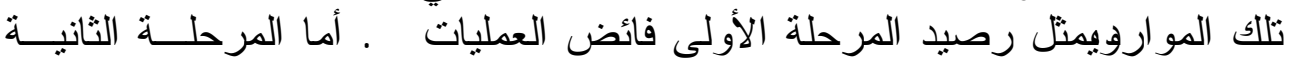

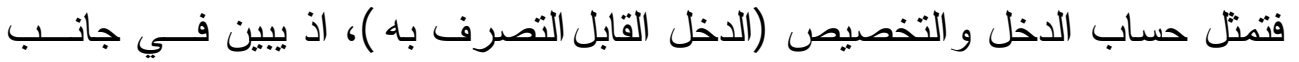

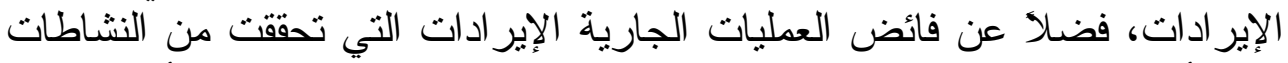

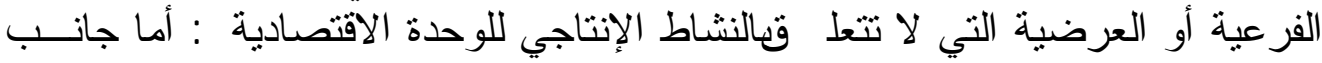

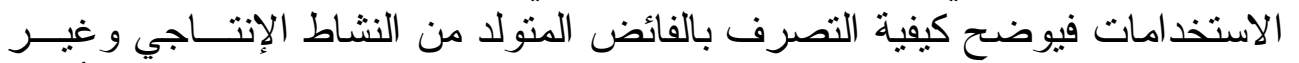
الإنتاجي كما يتضمن الحسابات المتقابلة لمطابقة الرصيد مع رصيد رصنيات حساب الأرباح ويمثل رصيد هذه المرحلة الفائض القابل للتوزيع ويأخذ الثكل الأتي: 


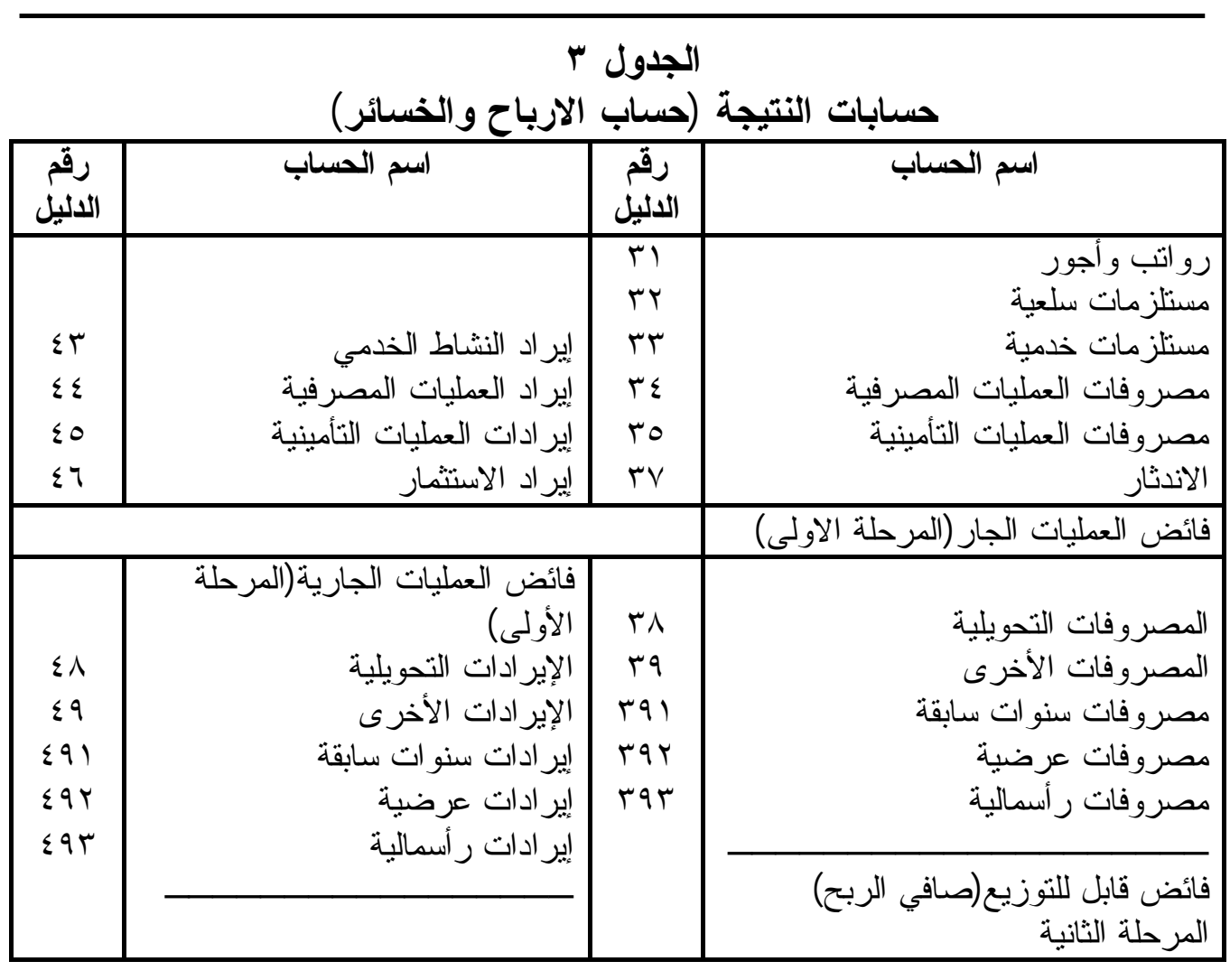

و عند قيام الباحثان بالإطلاع على السجلات و الحسابات الختامية المعدة عــن فئن

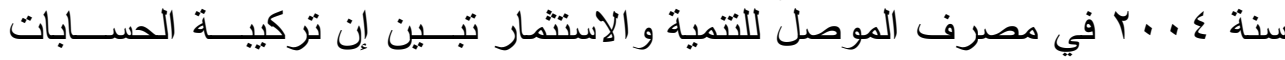

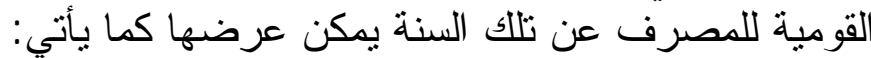

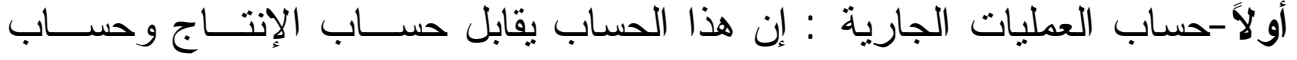

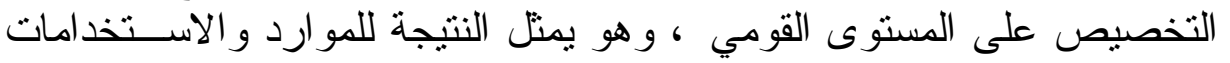
وينقسم إلى مرحلتين:

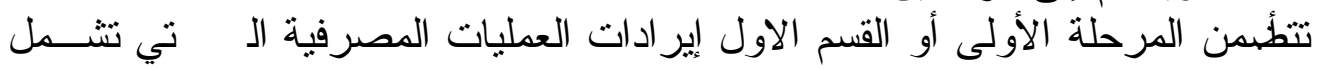

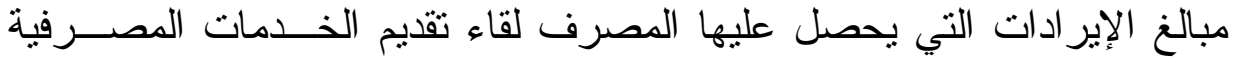

ا . فو ائد القروض الممنوحة.

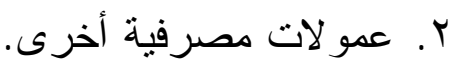

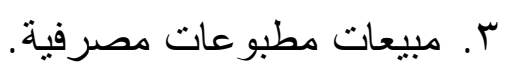

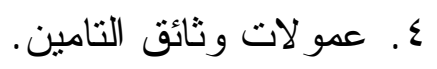


الجليلي و خضر [rr] تقييم الحسابات القومية في مصرف الموصل.

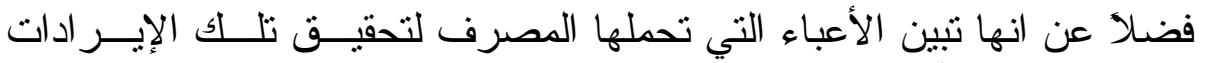

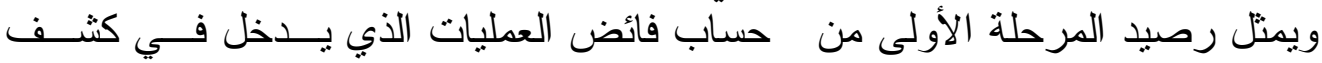
القيمة المضافة.

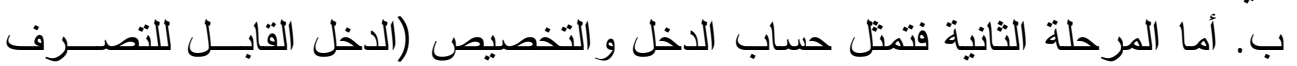

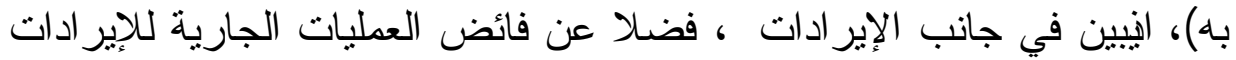

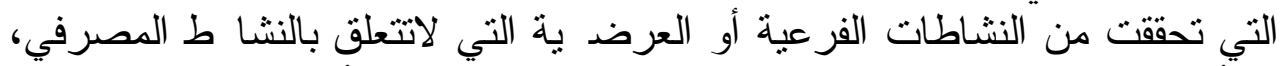

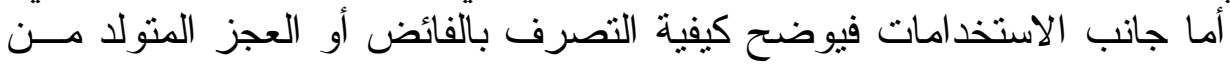

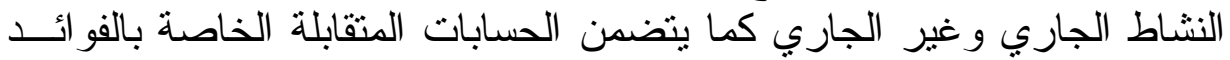

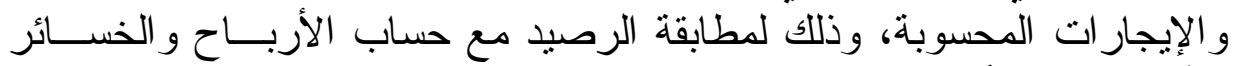
ويأخذ الثكل الأتي :

\begin{tabular}{|c|c|c|}
\hline \multicolumn{3}{|c|}{ 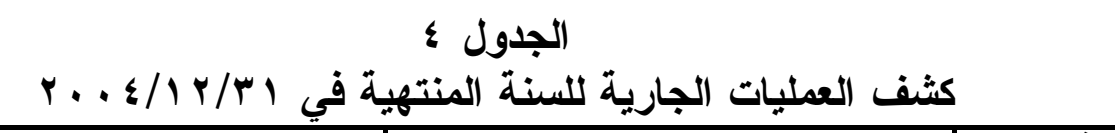 } \\
\hline$r \ldots \varepsilon$ & البيان & رقم الدليل \\
\hline 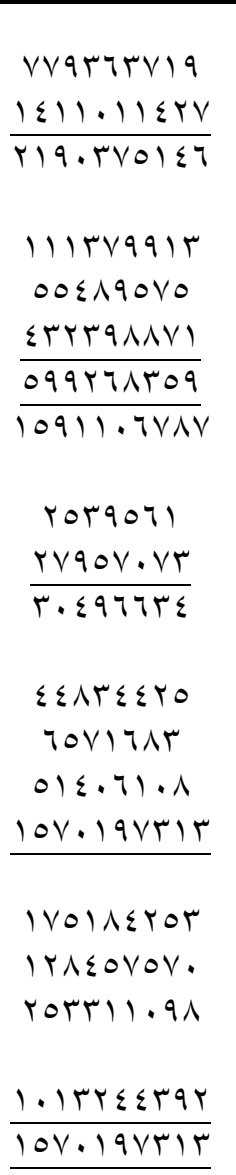 & 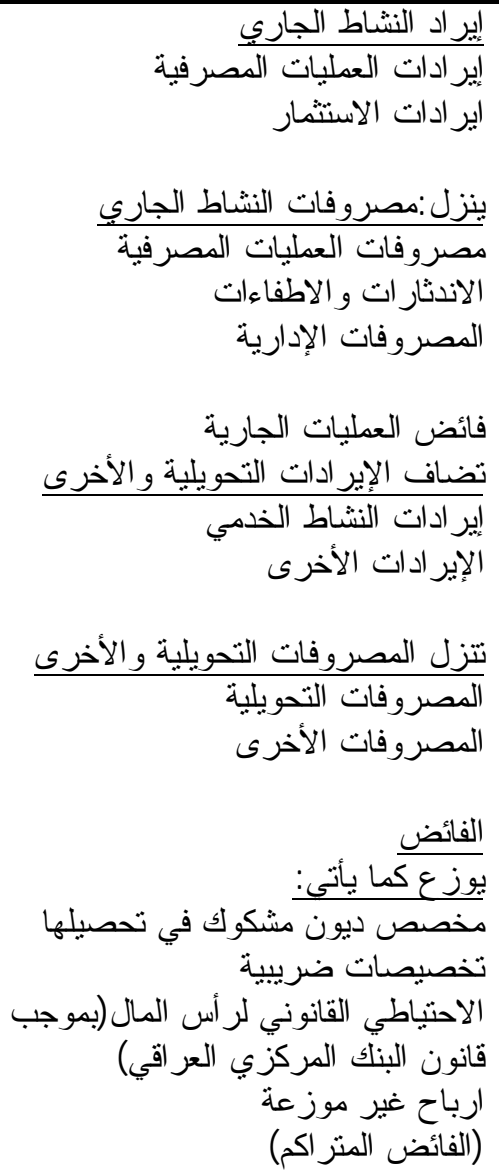 & $\begin{array}{c}r \varepsilon \\
r v \\
r / r / T /\end{array}$ \\
\hline
\end{tabular}


(rq) 10 [ [ [ب] كلبة الادارة و الاقتصاد/جامعة الموصل

كثف القيمة المضافة : يتم أعداد هذا الكثف في نهاية السنة المالية عند إعداد

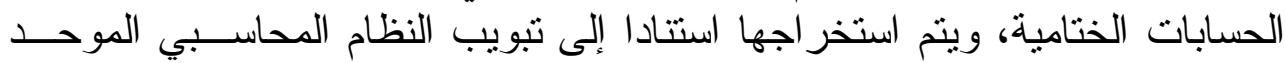

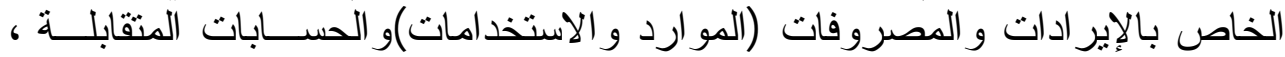

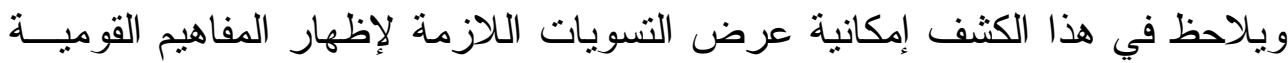

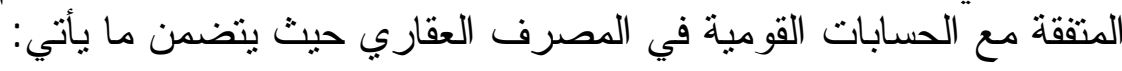

\section{- الجدول}

كثف توزيع القيمة المضافة الإجمالية بسعر تكلفة عوامل الإنتاج للسنة المنتهية r. . .

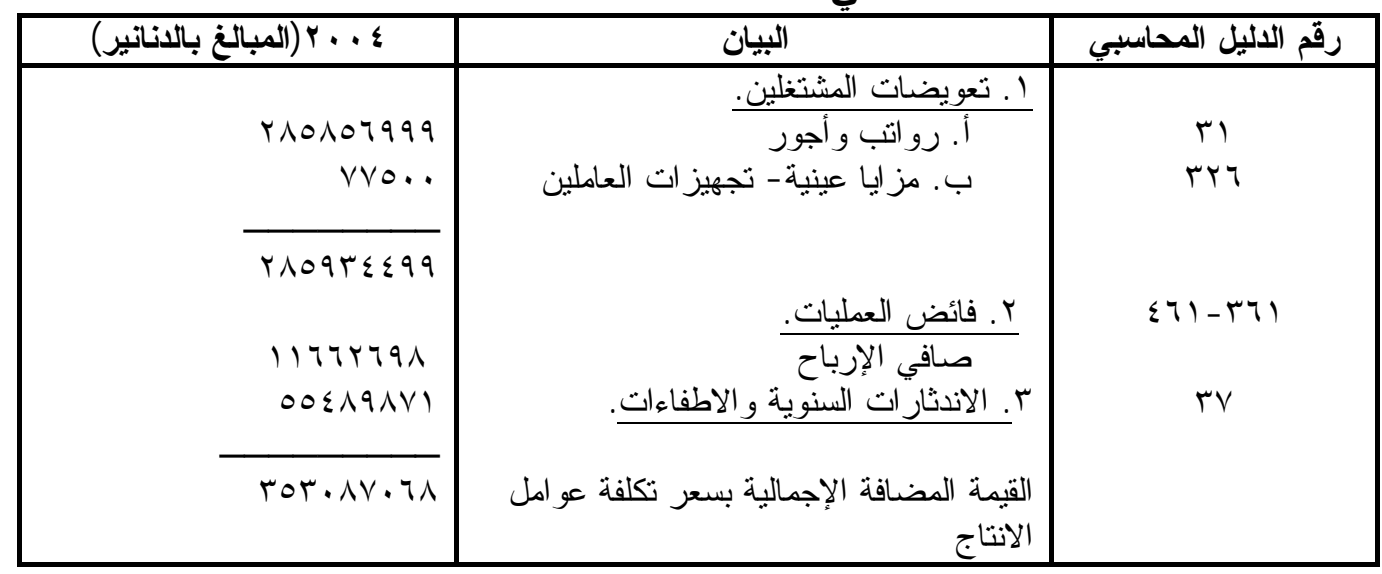

\section{الجدول 7}

كثف القيمة المضافة الإجمالية بسعر تكلفة عولامل الإنتاج للسنة المنتهية في

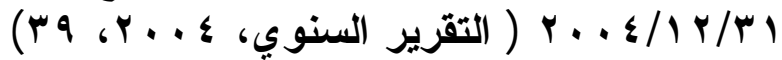

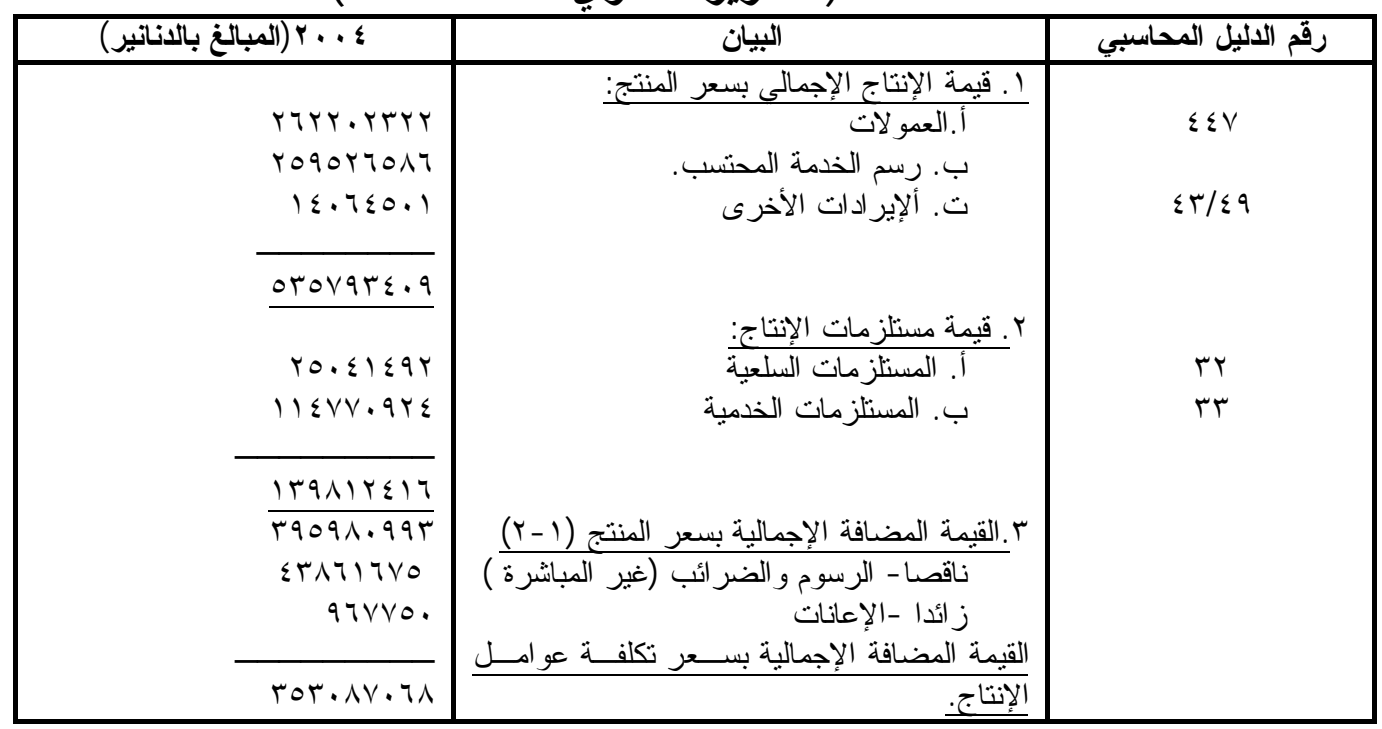




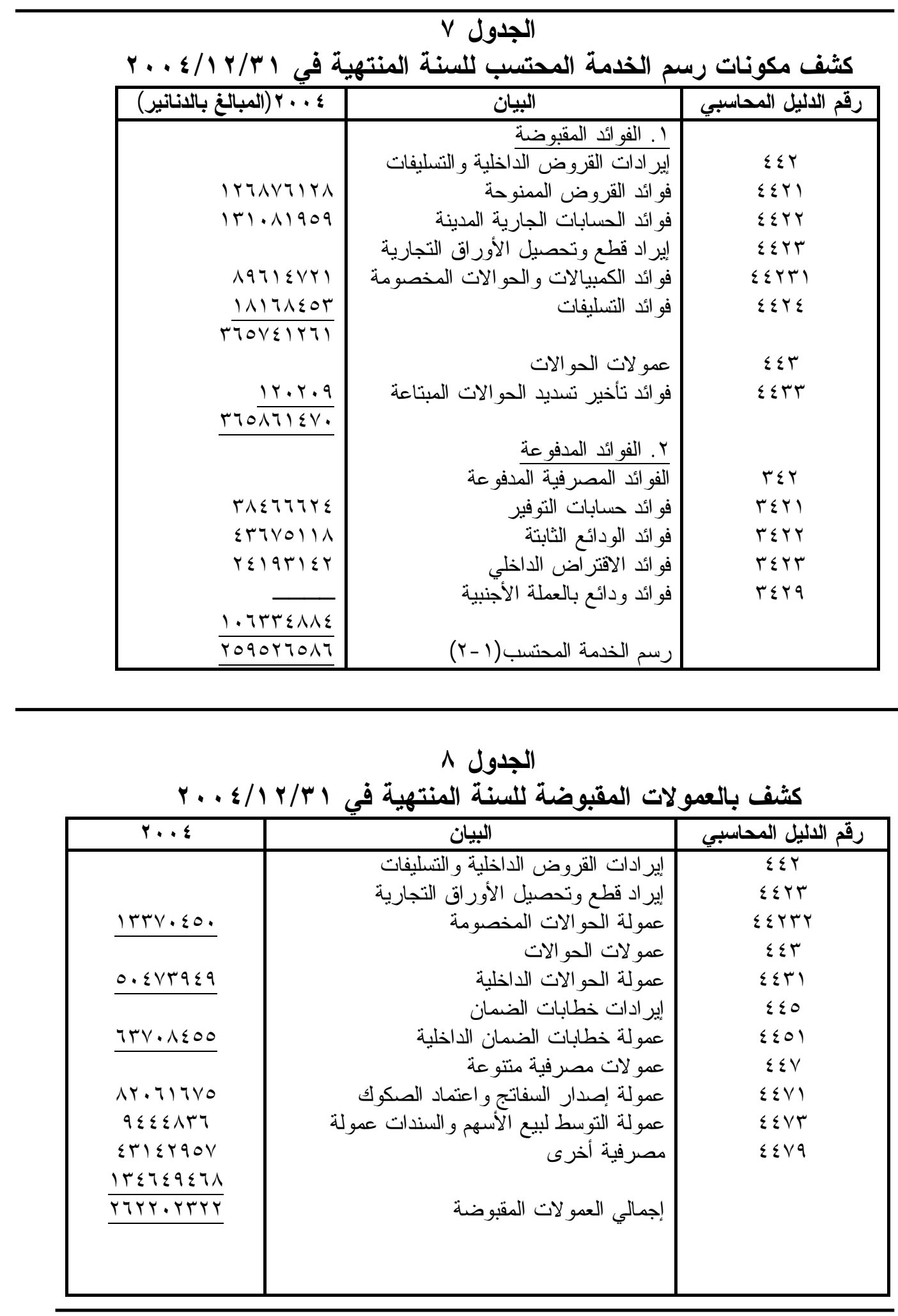


الاستتتاجات و التوصيات

انتهى الباحثان من خلاجل هذه التهات الدر اسة الى الاستتتاجات الاتية:

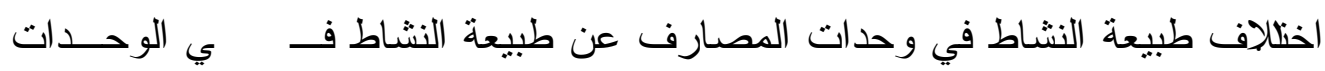

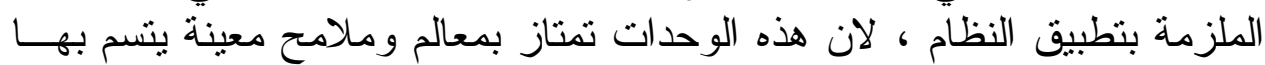

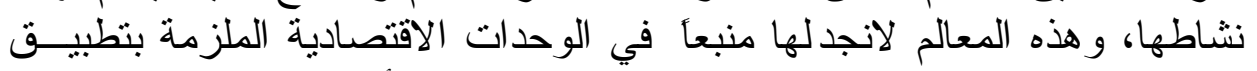

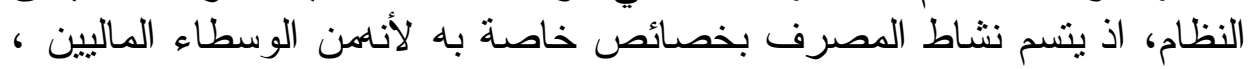

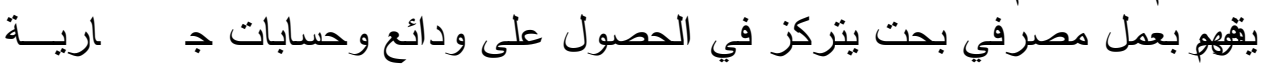

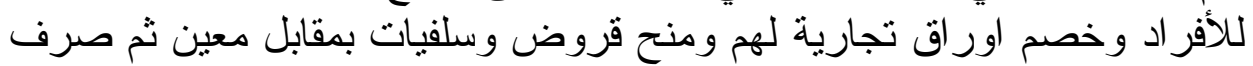

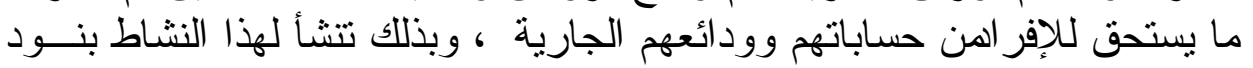
محاسبية معينة.

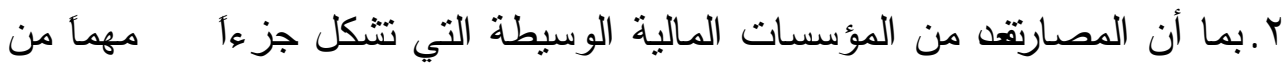

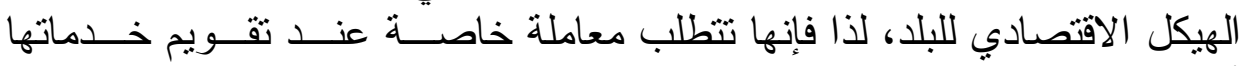

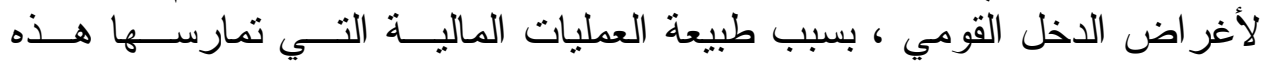

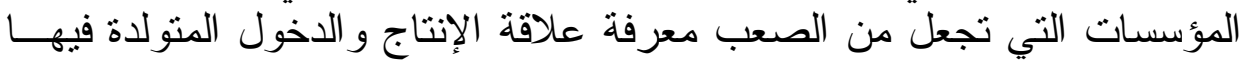

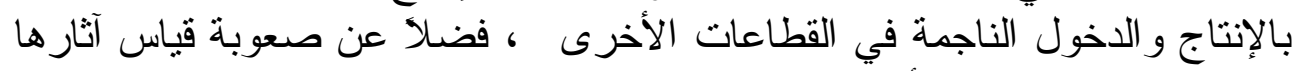

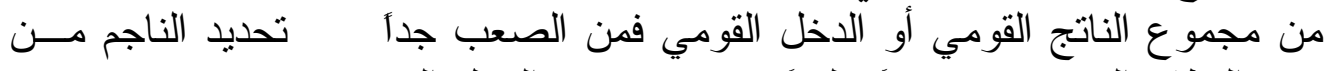

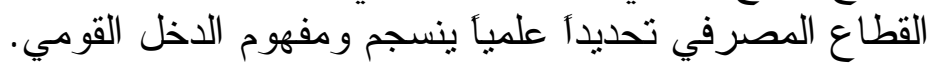

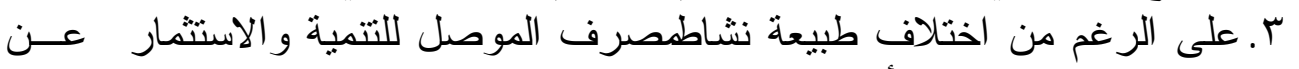

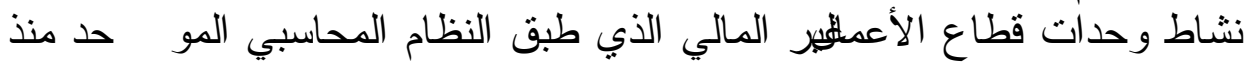

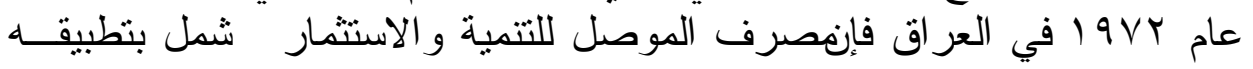

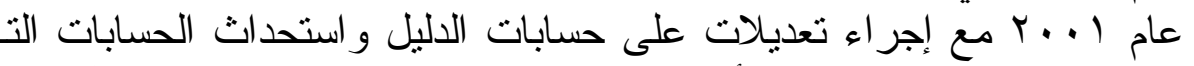

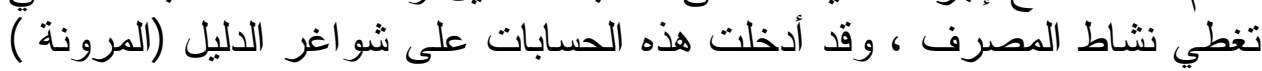

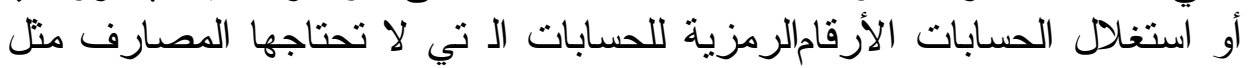

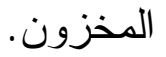

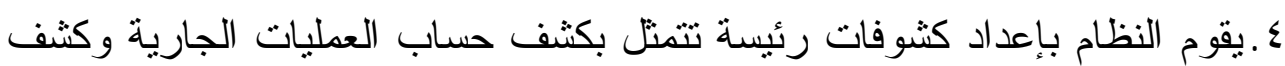

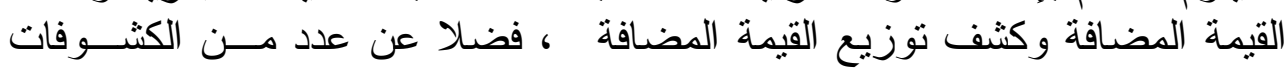

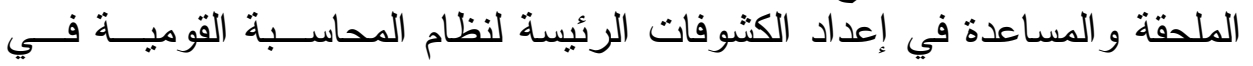

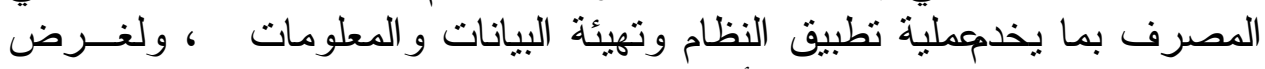

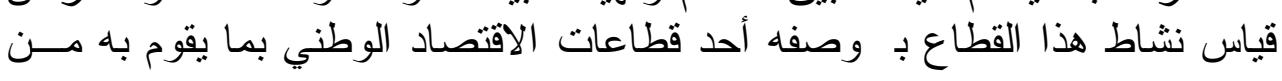

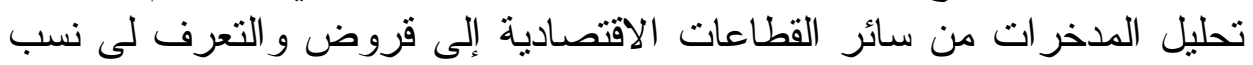

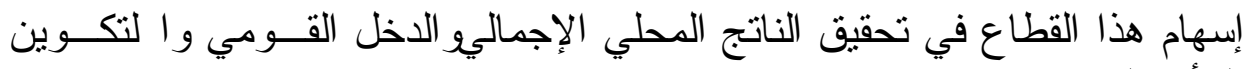

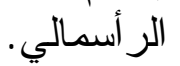

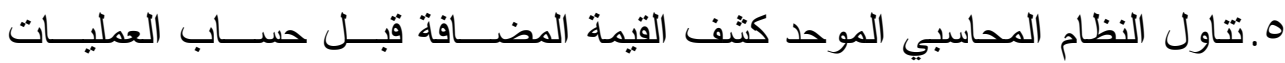

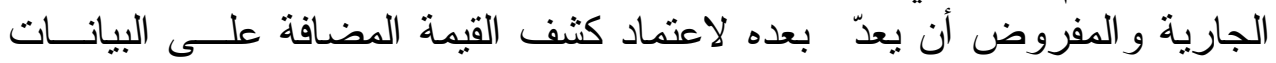

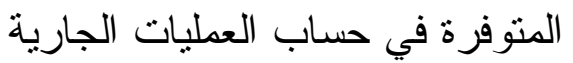




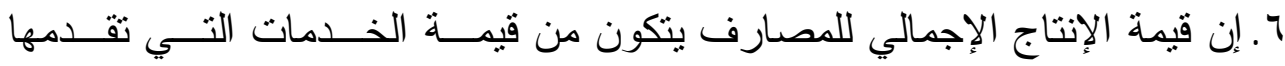

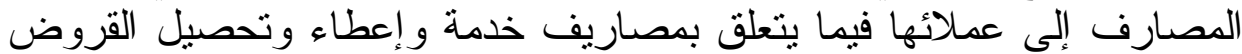

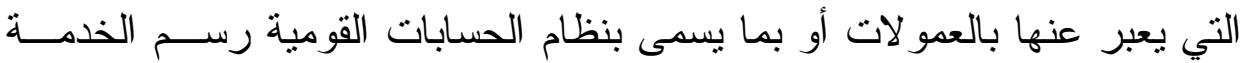

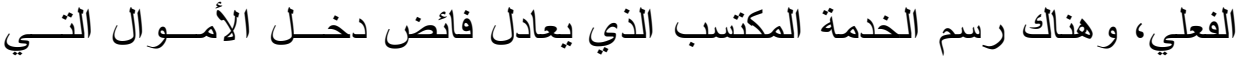

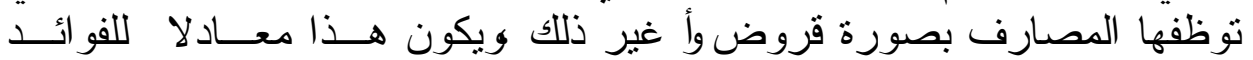

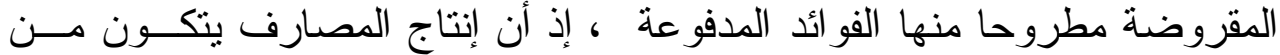

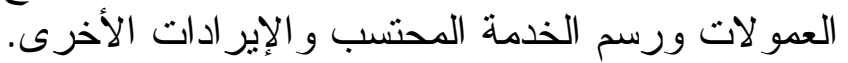

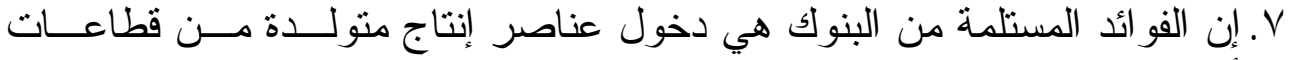

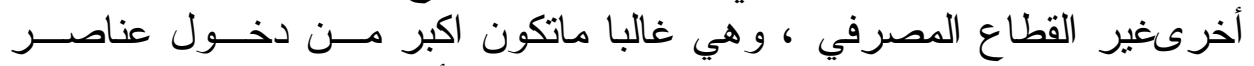

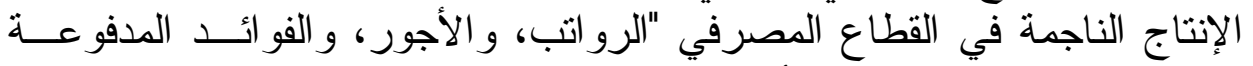

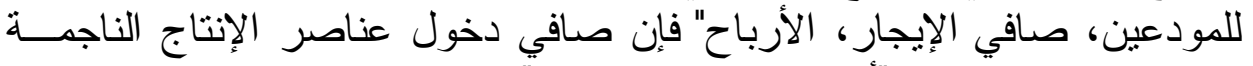

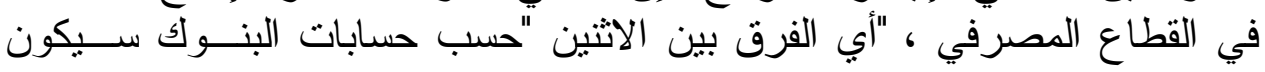

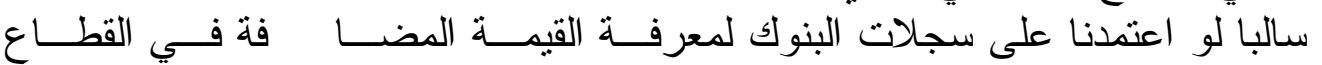

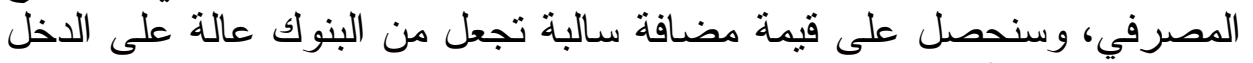

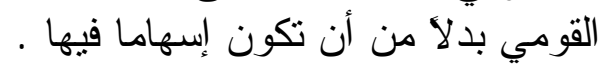

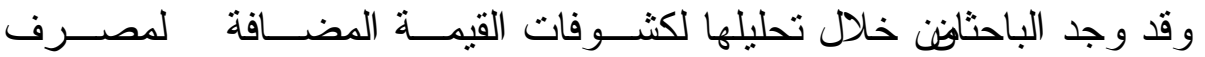

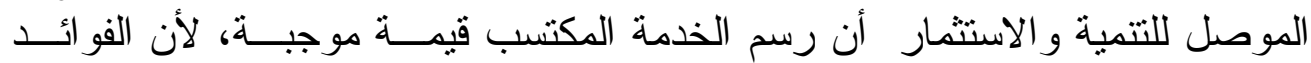

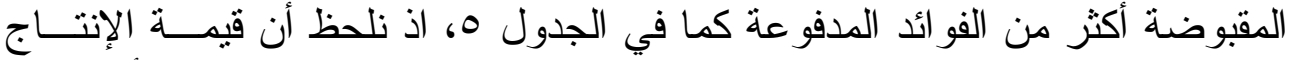

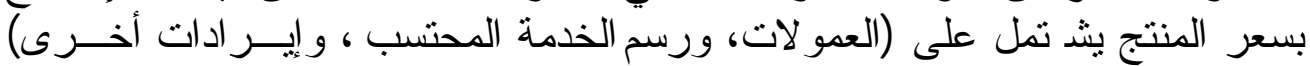

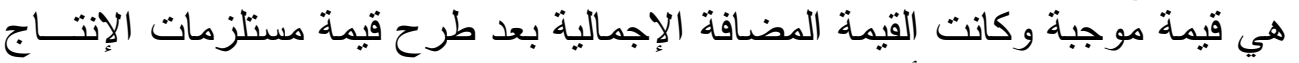

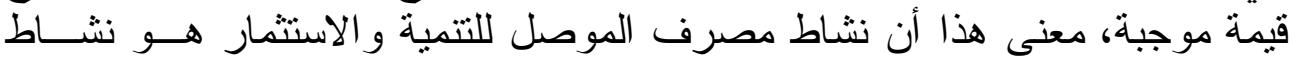

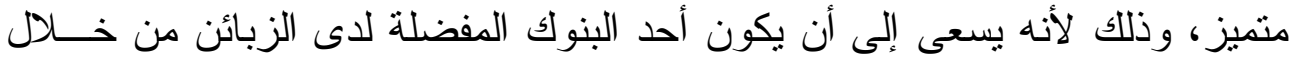

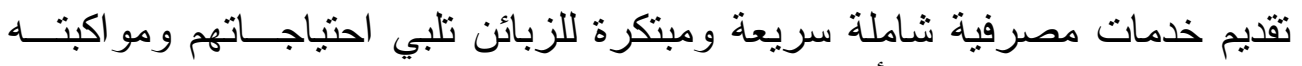

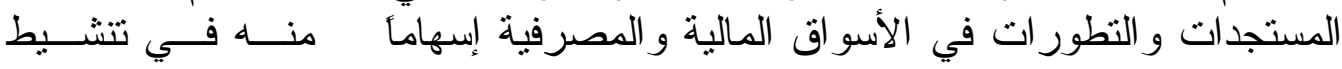
الفعاليات الاقتصادية و المالية.

\section{المراجع (الهر \\ أولاً - المر اجع باللإة العربية}

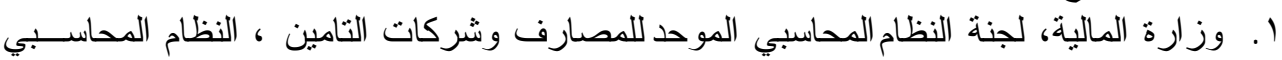

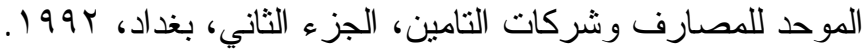

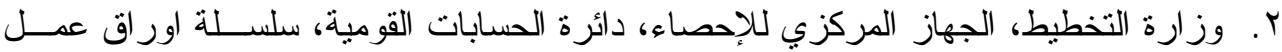

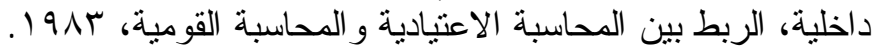

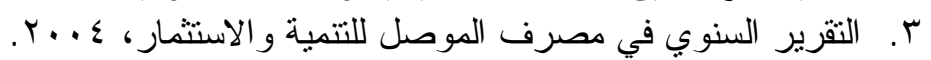

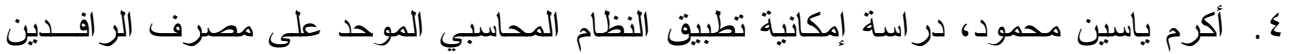

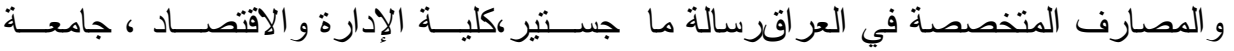




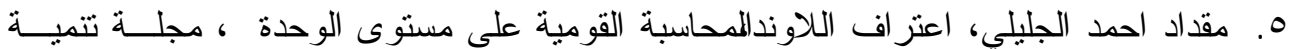

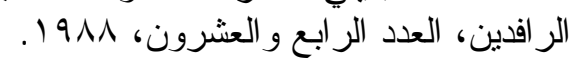

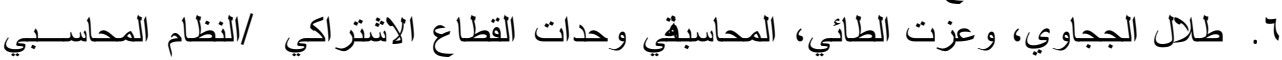

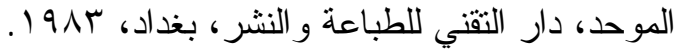

V. . عباس مهدي الثنير ازي،أصول المحاسبة القومية ،دار النهضة العربية ، كلية التجارة، جامعة

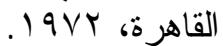

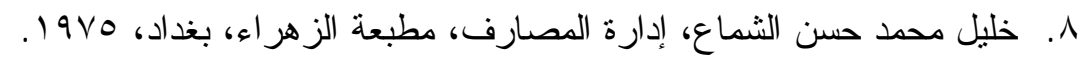

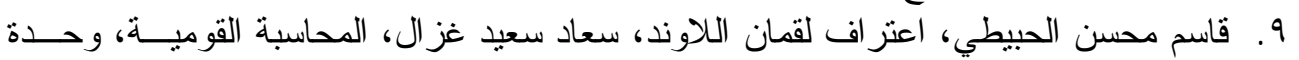

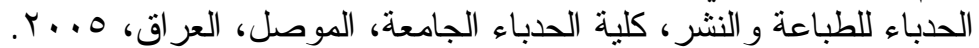

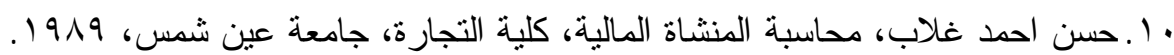

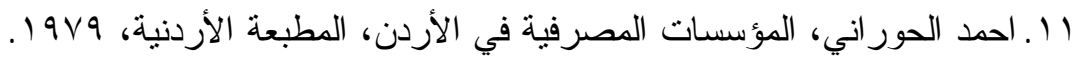

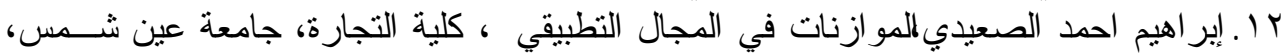
.1919

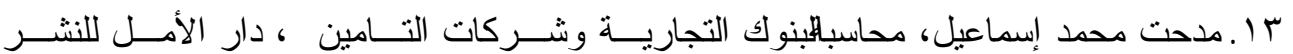

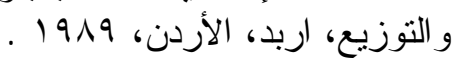

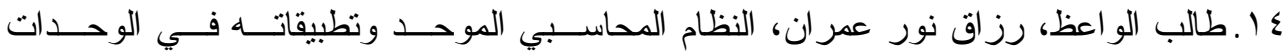

الاقتصادية، وزارة التعليم العالي و البحث العلمي، هيئة المعاهد الفنية، ، 199. 19.

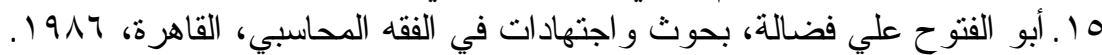

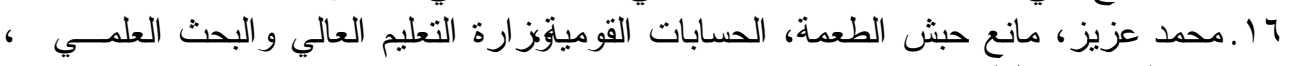

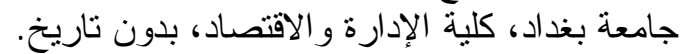

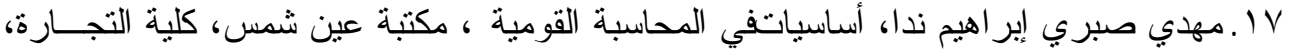

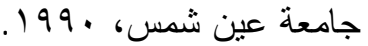

1 ا ـ جو اد هاثشلكسابات القومية المؤسسة العربية للار اسات و النشر ، بيروت،تشـرين الاول ، $.19 \vee r$

\section{ثانياً - المر اجع باللغة الاجنبية}

1. Fredc. Yeager, Financial Institution Management Text and Cases, Third Edition, NelieSettz, 1989.

2. Willsomore, A .W. ,Business Budgets and Budgetory Control, Sir Isac Pitman and Sons L.T.D ,1960. 